\title{
An assessment of the wind influence in local inertial 1D hydrodynamic flow routing
}

3

7

\section{ABSTRACT}

${ }^{9}$ One-dimensional (1D) bydrodynamic modeling studies generally do not take into account the influence of wind, although literature experiences

${ }^{10}$ demonstrate the importance of this information in some cases. In this context, the present work had the objective to investigate this matter further,

11 studying the influence of wind on bydrodynamic 1D modeling results and proposing an abacus for the rapid verification of the possible maximum

12 influence of a wind on a simulation. In order to carry out the work we propose a modified version of the inertial flow routing method including the

${ }_{13}$ wind shear stress. Several tests were performed to assess model stability and to understand further the wind influence on river flow conditions. As a

${ }^{14}$ result, an equation and an abacus were proposed to estimate maximum percentage depth variations that can be caused by continuous wind influence

${ }^{15}$ under different characteristics of river flow and wind action. Results also showed that it is possible to obtain a stable solution with the addition of the

${ }^{16}$ wind shear stress, but time interval values should be carefully selected considering high disturbances due to wind influence.

${ }^{17}$ Keywords: Hydrodynamic Modelling, Wind Shear, Local Inertial Method

18

19

\section{${ }^{20}$ INTRODUCTION}

21

22

23 hydrodynamic models or hydrological models to simula

24 processes such as floods and droughts, to assess land use

25 and climate change effects in water resources, to develop

26 flood forecasting systems, to simulate water quality

${ }^{27}$ variations, among many other applications. These

28 algorithms can be developed considering one, two or three

${ }^{29}$ spatial dimensions. One-dimension (1D) is usually

${ }^{30}$ considered when simulating rivers (CHOW, 1988).

31 Usually hydrological and hydrodynamic models,

32 despite allowing for the simulation of complex

33 hydrodynamic systems, do not account for the wind

34 influence. Even though the wind can exert substantial effect

${ }^{35}$ over such systems. A good example of this importance can

36 be found in the work of Mashriqui et al. (2014), who

${ }^{37}$ proposed a flood forecasting tool for the river Potomac, a

38 wide river located near the cost of United States and hence

${ }^{39}$ very susceptible to wind influence. The authors concluded

40 that only the use of the HEC-RAS hydrodynamic model

41 (USACE, 2010), which considers the full Saint-Venant

${ }^{42}$ Equations, wouldn't be sufficient to predict water levels in

43 the river due to the non-consideration of wind influence.

44 Additionally, the authors advise that the inclusion of wind

${ }^{45}$ shear in the HEC-RAS model would aid to improve flood

46 forecasting systems for 14 coastal rivers in EUA.

47 In another study, Rámon et al. (2016) analyzed,

48 among other factors, wind influence in mixing in the

${ }^{49}$ confluence of two large rivers in Spain and concluded that

50 this influence, depending on wind direction and velocity,

51 can employ important modifications in the system.

52

Other wind effects relevance studies are reported
${ }^{53}$ in literature, and particularly in systems comprehending a

${ }^{54}$ river connected to an estuary, as (ESCOBAR et al., 2004;

${ }^{55}$ GONG et al., 2009; D'AQUINO et al., 2011;

${ }^{56}$ BACOPOULOS et al., 2012).

$57 \quad$ Indeed the wind influence plays an important role ${ }^{58}$ in the dynamics of large water bodies such as lakes and ${ }^{59}$ lagoons (Ji, 2008). Therefore, most 2D and 3D ${ }^{60}$ hydrodynamic models usually applied to simulate these ${ }^{61}$ systems include this effect, such as the models MIKE (DHI, 62 2011), IPH-A (BORCHE, 1996), Delft-3D (DELTARES, ${ }_{63}$ 2014), IPH-ECO (Fragoso et al., 2009) and POM ${ }^{64}$ (BLUMBERG; MELLOR, 1987). But, despite the ${ }^{65}$ experiences showing that the account of wind effects in 1D ${ }^{66}$ hydrodynamic models can be beneficial, it is not a common ${ }^{67}$ practice.

68 Considering the exposed, the present study aimed ${ }^{69}$ to further investigate the possibility of including the wind ${ }^{70}$ shear effects in a 1D hydrodynamic flow routing method, 71 and to better understand how the wind would affect one 72 dimensional river simulations.

73 To accomplish with these objectives, the present 74 study was conducted considering two stages, as follows:

75 - Stage 1: Simulation of different scenarios of 76 hypothetical river reaches to verify stability and 77 better understand wind influence in the equations;

78 - Stage 2: Proposition of an equation and an abacus 79 to calculate maximum variations of water level due 80 to continuous wind stress.

81 The hydrodynamic flow routing method tested in 82 the present study was the local inertial method, based in a ${ }^{83}$ simplification of the Saint-Venant Equations. As far as we 
${ }^{1}$ concern, this method has never been previously applied in

2 the literature considering wind friction terms.

3 The full Saint-Venant Equations are known to ${ }^{4}$ describe one-dimensional non-permanent flow and are ${ }^{5}$ vastly applied (CUNGE et al., 1980; CHANSON, 2004).

${ }^{6}$ However, considering that hydrological models are used to

${ }^{7}$ simulate all or most of the processes that occur in

${ }^{8}$ hydrological systems, simpler flow routing methods than the

${ }^{9}$ full Saint-Venant Equations are commonly used

${ }^{10}$ (HODGES, 2013). These methods include, for example, the

${ }^{11}$ Muskingum-Cunge method (CUNGE, 1969; Collischonn et

${ }^{12}$ al., 2007), the Muskingum method (McCARTHY, 1938;

${ }^{13}$ NEITSCH et al., 2002; HATTERMANN et al., 2005) and

${ }^{14}$ linear reservoir methods (NGO-DUC et al., 2007;

${ }^{15}$ DECHARME et al., 2008). Due to simplifications. these

${ }^{16}$ methods do not allow for the simulation of floodplain

${ }^{17}$ storage and backwater effects.

The local inertial method, also called only 19 "inertial", proposed by Bates et al. (2010), poses as a ${ }^{20}$ promising alternative to the simple methods used in ${ }^{21}$ hydrological models (Fan et al., 2014). The algorithm only 22 excludes the advective inertial term of the Saint-Venant ${ }^{23}$ dynamic equation and, therefore, allows for the simulation

${ }^{24}$ of storage in floodplains and backwater effects. The authors

${ }^{25}$ Fan et al. (2014) and Montero et al. (2013), for example,

${ }^{26}$ verified similar results when applying the inertial method

27 and the full Saint-Venant equations for one-dimension

${ }^{28}$ simulations.

29 Motivated by the good performance of inertial ${ }^{30}$ equations testing's, Pontes et al. $(2015,2017)$ proposed a ${ }^{31}$ modified version of the MGB-IPH hydrological model ${ }^{32}$ (Collischonn et al., 2007) using the inertial flood routing ${ }^{33}$ algorithm and applied the model successfully in the

${ }^{34}$ Araguaia River basin, which comprehends very large

35 floodplain areas. This version of the model was also applied

${ }^{36}$ by Lopes $(2015,2017)$, who simulated basins and lagoon

${ }^{37}$ systems obtaining satisfactory results of water levels inside

${ }^{38}$ the lagoons. Lopes $(2015,2017)$ concluded that the

${ }^{39}$ combination of the inertial routing and storage simulations

40 inside the lagoon, even considering only one-dimension,

${ }^{41}$ were satisfactory to estimate water levels and inundated

42 areas in the complex hydrodynamic and hydrological system

${ }^{43}$ of the Patos Lagoon basin (southern Brazil).

44

The inertial flow routing method is also the basis

${ }^{45}$ of hydrodynamic models such as LISFLOOD-PF (BATES

${ }^{46}$ et al., 2010) and Cama-Flood (YAMAZAKI et al., 2013).

47 The latter was applied in a global scale and compared to the

${ }^{48}$ previous version of the model, which was based on the non-

49 inertial equations. The authors concluded that, considering

${ }^{50}$ explicit numerical approximations, the inertial method

${ }^{51}$ required larger time intervals than the non-inertial method,

52 resulting in more stable and efficient simulations.

53 The next section of this paper presents the 54 theoretical arrangement of the study. Further sections ${ }^{55}$ present the two stages tests, results, discussions and
${ }^{56}$ conclusions.

57

58 WIND STRESS IN THE LOCAL INERTIAL ${ }^{59}$ FLOW ROUTING ALGORITHM

60

61 The inertial flow routing algorithm is based on a 62 simplification of the Saint-Venant equations that neglects

63 only the advective inertial terms of the dynamic equation

${ }^{64}$ (BATES et al., 2010). The resulting formulation is presented ${ }^{65}$ by equations 1 (Continuity) and 2 (Dynamic):

$66 \frac{\partial A}{\partial t}+\frac{\partial Q}{\partial x}=0$

$67(1)$

${ }_{68} \frac{\partial Q}{\partial t}+g \cdot A \frac{\partial h}{\partial x}-g \cdot A \cdot S_{o}+g \cdot A \cdot S_{f}=0$

${ }^{69}$ in which A represents the cross-sectional area $\left(\mathrm{m}^{2}\right), \mathrm{Q}$ ${ }^{70}$ represents water flow $\left(\mathrm{m}^{3} / \mathrm{s}\right), \mathrm{x}$ is the longitudinal distance ${ }^{71}(\mathrm{~m}), \mathrm{t}$ is the time $(\mathrm{s})$, So is the bottom slope $(\mathrm{m} / \mathrm{m}), \mathrm{h}$ is the 72 river depth $(\mathrm{m}), \mathrm{Sf}$ is the friction slope $(\mathrm{m} / \mathrm{m})$ and $\mathrm{g}$ is the ${ }^{73}$ gravitational acceleration $\left(\mathrm{m} / \mathrm{s}^{2}\right)$. The first term of Equation ${ }^{74} 2$ represents de conservation of momentum and the ${ }^{75}$ remaining terms represent external forces that act in the ${ }^{76}$ flow: pressure, gravitational and frictional resistance, 77 respectively.

78 The wind stress is a tangential force that acts on 79 the water surface and can be written as (Ji, 2008):

${ }^{80} \tau=\rho_{\text {air }} \cdot C_{d} \cdot U^{2}$

$81 \quad(3)$

82 in which $\varrho_{\text {air }}$ is the air density $\left(\mathrm{kg} / \mathrm{m}^{3}\right), \mathrm{Cd}$ is the wind stress ${ }^{83}$ coefficient (dimensionless) and $\mathrm{U}$ is the wind velocity in the ${ }^{84}$ direction of the flow $(\mathrm{m} / \mathrm{s})$.

85 To add the wind stress force to the dynamic ${ }^{86}$ equation of the inertial method some modifications have to ${ }^{87}$ be made to Equation 3: (i) Considering that the wind stress ${ }^{88}$ acts in the water surface and that the longitudinal distance 89 in the differential dynamic equation (Equation 2) is 90 infinitesimal, the equation 3 should be multiplied by the ${ }^{91}$ width of the river reach; (ii) The density of air should be 92 divided by the water density as Equation 2 was previously ${ }^{93}$ divided by this term in its formulation; (iii) The wind 94 velocity should be considered as a vector and maintain the ${ }^{95}$ wind direction. This can be done by multiplying the wind ${ }^{96}$ velocity by its absolute value. The resulting dynamic ${ }^{97}$ equation is Equation 4:

${ }_{98} \frac{\partial Q}{\partial t}+g \cdot A \frac{\partial h}{\partial x}-g \cdot A \cdot S_{o}+g \cdot A \cdot S_{f}-B \cdot C_{D} \cdot|U| \cdot U=0$

${ }^{99}$ in which the relative density of air was combined to the wind 100 stress coefficient in the parameter $C_{D}$ (dimensionless) here 101 called wind friction coefficient. B is the river width (m). 102 Positive wind velocities favor the flow and negative values 
${ }^{1}$ of $\mathrm{U}$ act against flow direction.

2 Assuming a rectangular channel, that Sf can be ${ }^{3}$ estimated using the Manning equation, and using the explicit

${ }^{4}$ finite differences numerical approximation proposed by

${ }^{5}$ Bates et al. (2010), progressive in time and centered in space,

${ }^{6}$ Equation 4 can be written as:

${ }^{7} Q_{i+\frac{1}{2}}^{k+1}=\frac{\left(\left(Q_{i+\frac{1}{2}}^{k}\right)-g \cdot B \cdot \Delta t \cdot\left(h_{i+\frac{1}{2}}^{k}\right) \frac{\left(y_{i+1}^{k}-y_{i}^{k}\right)}{\Delta x}+\Delta t \cdot B \cdot C_{D} \cdot|U| \cdot U\right)}{\left(\begin{array}{c}g \cdot \Delta t \cdot\left(\left|q_{i+\frac{1}{2}}^{k}\right|\right) \cdot n^{2} \\ \left.1+\frac{B\left(h_{i+\frac{1}{2}}^{k}\right)^{7 / 3}}{7}\right)\end{array}\right.}$

${ }^{8}$ in which $\mathrm{i}$ refers to space, $\mathrm{k}$ refers to time, $\Delta \mathrm{t}$ is the time

${ }^{9}$ interval, $\Delta \mathrm{x}$ is the length of the river section, and $\mathrm{y}$

${ }^{10}$ represents the water level. The position $i+1 / 2$ represents the

11 end of the section $i$, the position $i-1 / 2$ represents the

12 beginning of the section $I$, and $i$ represents the center of the

${ }^{13}$ section, for example, $Q_{i+\frac{1}{2}}^{k+1}$ is the flow in the end of the

${ }^{14}$ section $\mathrm{i}$ in time interval $\mathrm{k}+1, y_{i+1}^{k}$ represents the water level

${ }^{15}$ in the center of section $i+1$ and in the kth time interval.

${ }^{16} h_{i+\frac{1}{2}}^{k}$ refers to the depth located between sections $i$ and $i+1$

17 in the kth time interval, calculated by Equation 6.

${ }^{18} h_{i+\frac{1}{2}}^{k}=\max \left[y_{i}^{k} ; y_{i+1}^{k}\right]-\max \left[z_{i} ; z_{i+1}\right]$

${ }^{19}$ where $Z_{i+1}$ is the bottom level of the river section $\mathrm{i}+1$.

${ }^{20}$ Using the same numerical scheme, Equation 1 can be ${ }^{21}$ written:

${ }^{22} \mathrm{~h}_{\mathrm{i}}^{\mathrm{k}+1}=\mathrm{h}_{\mathrm{i}}^{\mathrm{k}}-\frac{\Delta \mathrm{t}}{B \cdot \Delta \mathrm{x}}\left(\mathrm{Q}_{\mathrm{i}+\frac{1}{2}}^{\mathrm{k}+1}-\mathrm{Q}_{\mathrm{i}-\frac{1}{2}}^{\mathrm{k}+1}\right)$

23 In the method algorithm, equations 6,5 and 7 are ${ }^{24}$ applied sequentially, first by knowing as an initial condition 25 the water levels and flows in all sections in the first time ${ }^{26}$ interval. First equation 6 is applied to calculate $h_{i+\frac{1}{2}}^{k}$ in all ${ }^{27}$ sections in time interval $\mathrm{k}$, then Equation 5 in applied to ${ }^{28}$ calculate de flow in all sections in time interval $\mathrm{k}+1$ and

${ }^{29}$ finally Equation 7 is applied to calculate the water depth in

30 all sections in time $\mathrm{k}+1$; which allows for the calculation of

${ }^{31}$ water level knowing the values of $\mathrm{z}$ in all sections.

32 Because the algorithm was derived using an ${ }^{33}$ explicit numerical method, there is the need to respect the

${ }^{34}$ Courant-Friedrichs-Levy condition. Therefore, the

${ }^{35}$ definition of the time interval must satisfy Equation 8:

${ }^{36} \Delta t=\alpha \frac{\Delta x}{\sqrt{\mathrm{gh}}}$

${ }^{37}$ in which $\alpha$ is a coefficient equal to or lower than 1 . Values ${ }^{38}$ lower than 0.9 are advised (Bates et al.,2010; Yamazaki et al., 39 2013).

40

\section{${ }^{41}$ STAGE 1: SIMULATION EXPERIMENTS}

42

43 A hypothetical river reach was considered in this ${ }^{44}$ study. The definition of its characteristics was based on the ${ }^{45}$ lower Jacuí River (RS, Brazil) in the reach between the ${ }^{46}$ confluence with Taquari River (RS, Brazil) and the Guaíba ${ }^{47}$ Lake (RS. Brazil). This reach is very likely to be influenced ${ }^{48}$ by wind due to being in a flat area, having a large width, and ${ }^{49}$ being upstream to a large lake, which motivated its selection.

50 The reach has very low bed slope, assumed 1 ${ }^{51} \mathrm{~cm} / \mathrm{km}$. The average width is approximately $800 \mathrm{~m}$ and the 52 average flow is approximately $1000 \mathrm{~m}^{3} / \mathrm{s}$. The Manning ${ }^{53}$ coefficient of 0.03 was adopted and a $C_{D}$ value of $1 \times 10^{-6}$ was ${ }^{54}$ selected for the tests. The original reach has approximately $5550 \mathrm{~km}$ of length, however a $100 \mathrm{~km}$ length was considered in 56 the hypothetical reach to avoid the influence of boundary ${ }^{57}$ conditions on the flow. The upstream boundary condition ${ }^{58}$ used is a constant inflow and the downstream boundary ${ }^{59}$ condition assumed is a normal depth. The hypothetical ${ }^{60}$ reach and other parameters are resumed on Table 1. 61

62 Table 1. General reach characteristics and simulation parameters.

\begin{tabular}{|c|c|}
\hline Characteristics & Value \\
\hline Length & $100 \mathrm{~km}$ \\
\hline Simulation duration & $500 \mathrm{~h}$ \\
\hline$\Delta \mathrm{x}$ & $2 \mathrm{~km}$ \\
\hline$\alpha$ & 0.7 \\
\hline $\mathrm{B}$ & $1000 \mathrm{~m}^{3} / \mathrm{s}$ \\
\hline $\mathrm{S}$ & $800 \mathrm{~m}$ \\
\hline $\mathrm{n}$ & $0.01 \mathrm{~m} / \mathrm{km}$ \\
\hline $\mathrm{C}_{\mathrm{D}}$ & $1 \times 10^{-6}$ \\
\hline
\end{tabular}

64

65 ${ }^{66}$ constant wind profile, considering constant and continuous ${ }^{67}$ wind action; and (ii) a pulse wind profile, considering a pulse ${ }^{68}$ of wind with a $30 \mathrm{~h}$ duration. The profiles are displayed on ${ }^{69}$ Figure 1. In both profiles, the wind starts to act after 30 70 hours.

71 


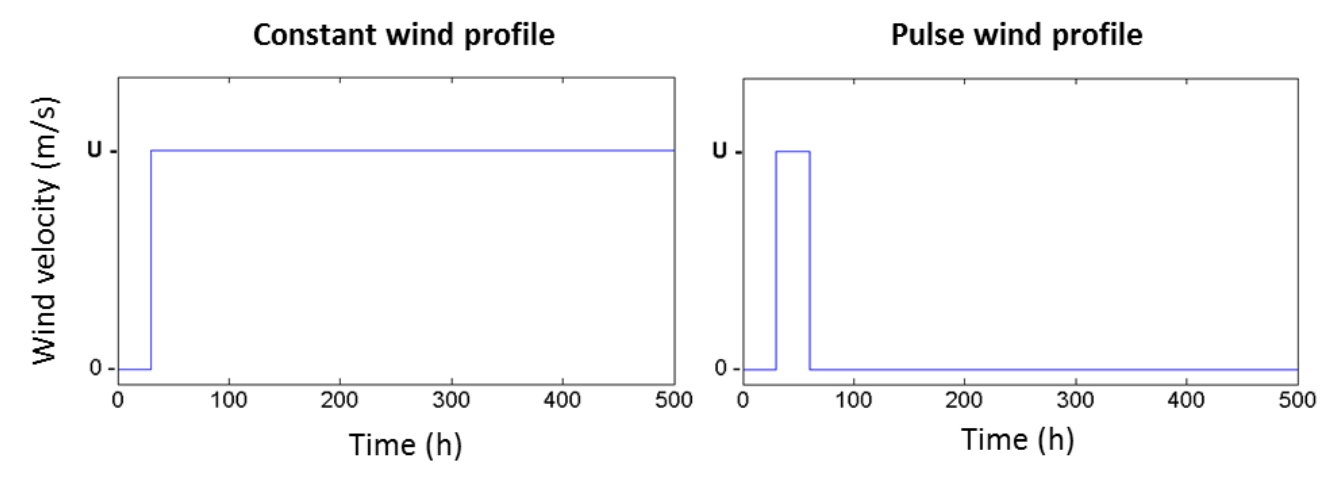

Figure 1: Wind action profiles.

Seven simulations were performed:

1. Simulation of the hypothetical river reach ${ }^{7}$ considering the constant wind influence (constant profile) 8 testing wind velocities and directions;

92 2. Simulation of the hypothetical river reach ${ }^{10}$ considering the $30 \mathrm{~h}$ pulse of wind (pulse profile) testing ${ }^{11}$ wind velocities and directions;

123 Simulation considering one extreme ${ }^{13}$ wind velocity and direction scenario $(-15 \mathrm{~m} / \mathrm{s}$, against flow

${ }^{14}$ direction) for pulse and constant profiles, testing reach ${ }^{15}$ lengths to verify influence of boundary conditions;

164 Simulation of the hypothetical river reach 17 testing low and high flow conditions considering the ${ }^{18}$ constant wind profile with $-10 \mathrm{~m} / \mathrm{s}$ wind velocity (against ${ }^{19}$ the flow);

$20 \quad 5$ S Simulation testing different values of bed ${ }^{21}$ slope using the constant wind profile with $-10 \mathrm{~m} / \mathrm{s}$ wind 22 velocity against the flow;

236 Simulation testing different values of ${ }^{24}$ reach width using the constant wind profile with $-10 \mathrm{~m} / \mathrm{s}$ ${ }^{25}$ wind velocity against the flow;
$26 \quad 7$ Simulation testing different values of ${ }^{27}$ wind friction coefficient using the constant wind profile ${ }^{28}$ with $-10 \mathrm{~m} / \mathrm{s}$ wind velocity against the flow;

29 In all simulations figures of flow and water depth ${ }^{30}$ variation with time are presented displaying five equally ${ }^{31}$ spaced river sections (from the first section, displayed in 32 blue, to the last section, displayed in red). For scenarios 1 ${ }^{33}$ and 2, curves of water depth transversal profiles are ${ }^{34}$ presented displaying 10 time intervals (from the first time 35 interval, displayed in blue, to a selected interval based on ${ }^{36}$ results, called upper limit time interval (U.L), displayed in ${ }^{37}$ red).

38

\section{${ }^{39}$ Simulation 1 - Influence of a constant wind profile}

40 This simulation intended to verify the influence of ${ }^{41}$ constant wind action on the flow characteristics considering 42 six different wind velocities: $-5 \mathrm{~m} / \mathrm{s},-10 \mathrm{~m} / \mathrm{s},-15 \mathrm{~m} / \mathrm{s}, 5$ ${ }^{43} \mathrm{~m} / \mathrm{s}, 10 \mathrm{~m} / \mathrm{s}$ and $15 \mathrm{~m} / \mathrm{s}$. Results are displayed on figures 2 44 to 4 . On Figure 4, the upper limit (U.L.) time interval of the ${ }^{45}$ plotted curves was $300 \mathrm{~h}$.

46 47 


\section{Preprint}
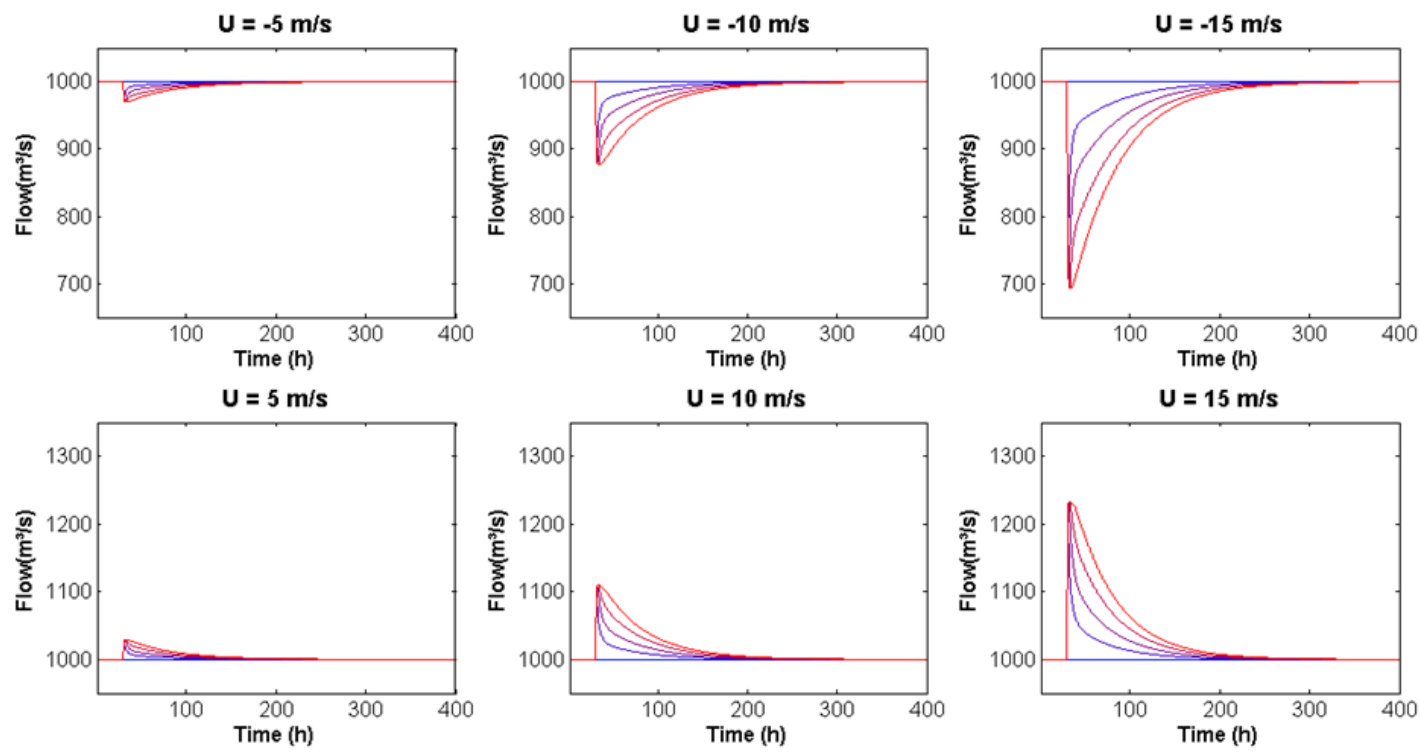

legend

- Inflow $-\mathrm{x}=\mathrm{L}^{*} 0.25-\mathrm{x}=\mathrm{L}^{*} 0.50-\mathrm{x}=\mathrm{L}^{*} 0.75-\mathrm{x}=\mathrm{L}$

Figure 1 - Flow hydrographs under continuous wind influence.
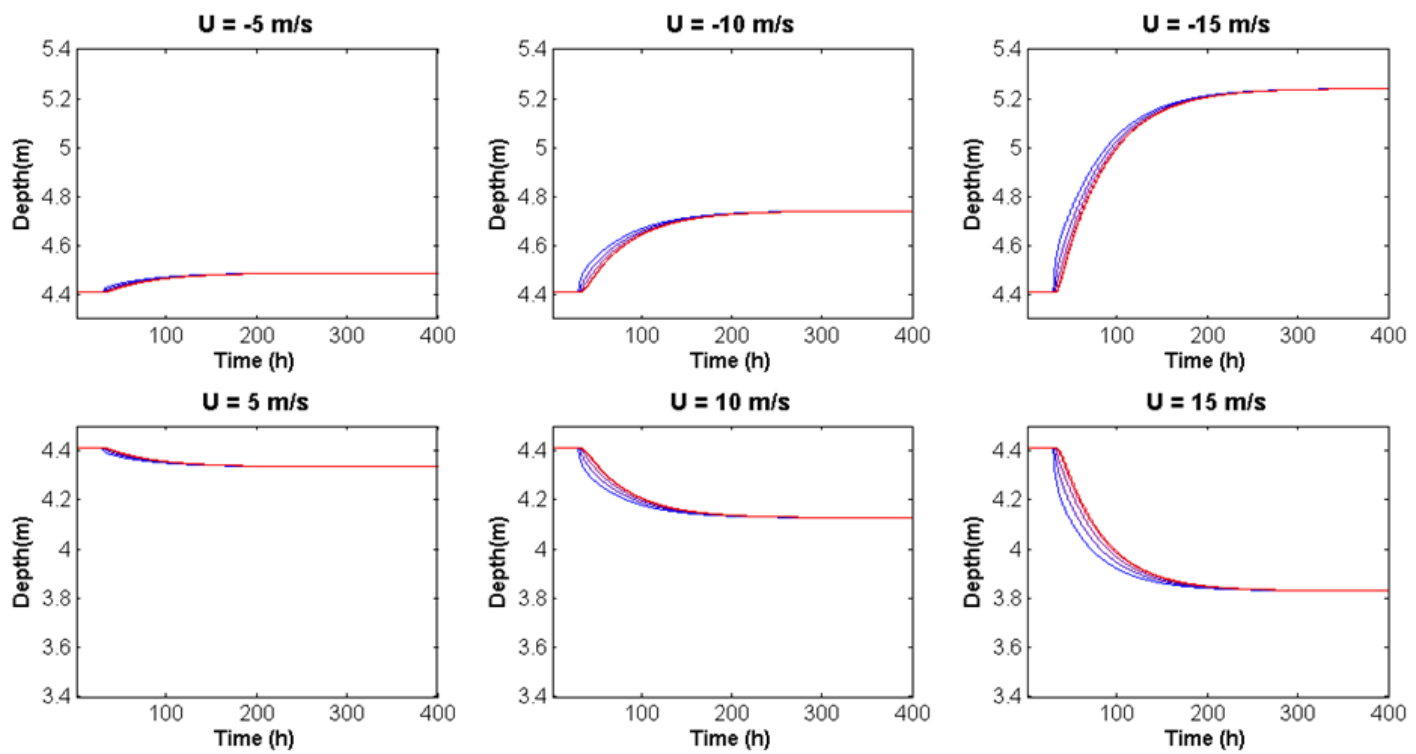

legend - Inflow $-\mathrm{x}=\mathrm{L}^{*} 0.25-\mathrm{x}=\mathrm{L}^{*} 0.50-\mathrm{x}=\mathrm{L}^{*} 0.75-\mathrm{x}=\mathrm{L}$

Figure 2- Water depth versus time under continuous wind influence. 

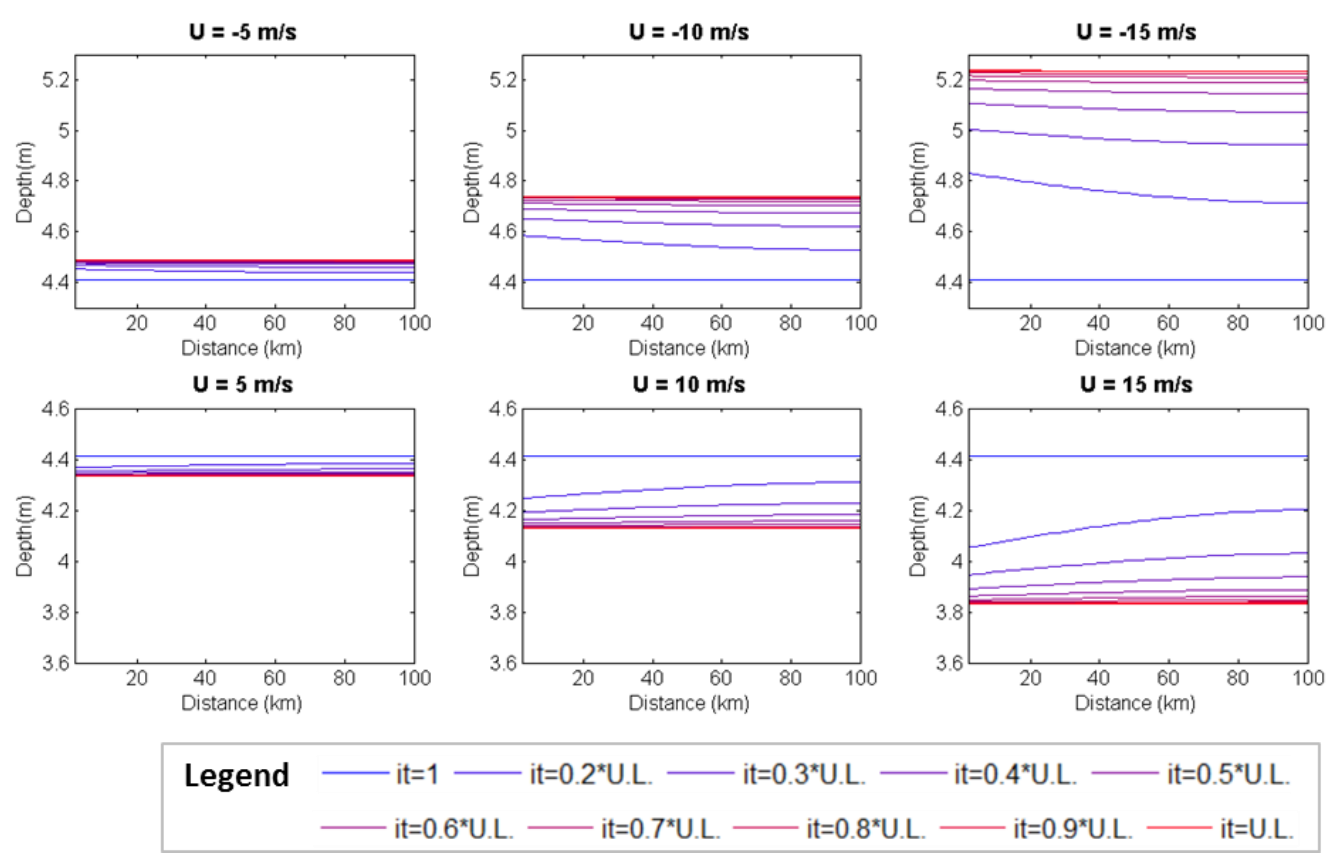

Figure 3 - Water depth longitudinal profiles under continuous wind influence

Figure 2 shows that once wind starts acting there ${ }^{6}$ is an immediate disturbance in flow which reaches its 7 maximum flow variation not long after wind started. ${ }^{8}$ Considering negative (positive) wind velocities, the variation ${ }^{9}$ is negative (positive) with an associated decrease (increase) ${ }^{10}$ in flow. Also, the greater the wind velocity is, the greater is ${ }^{11}$ the flow variation, e.g. for a wind velocity of $-15 \mathrm{~m} / \mathrm{s}$ the 12 flow in the last section can reach approximately $700 \mathrm{~m}^{3} / \mathrm{s}$, ${ }^{13}$ while considering a wind velocity of $-10 \mathrm{~m} / \mathrm{s}$, the flow in the ${ }^{14}$ last section has a maximum decrease to only approximately ${ }_{15}^{15} 870 \mathrm{~m}^{3} / \mathrm{s}$. In addition, absolute variations are greater for ${ }^{16}$ negative wind velocities, e. g. the maximum flow variation 17 in the last section associated to a wind with $-15 \mathrm{~m} / \mathrm{s}$ is 300 ${ }^{18} \mathrm{~m}^{3} / \mathrm{s}$, approximately $60 \mathrm{~m}^{3} / \mathrm{s}$ greater than the variation ${ }^{19}$ correspondent to $15 \mathrm{~m} / \mathrm{s}$.

20 After the maximum flow variation is reached soon ${ }^{21}$ after the wind started, it begins to decrease progressively ${ }^{22}$ until the flow returns to the previous value of $1000 \mathrm{~m}^{3} / \mathrm{s}$. ${ }^{23}$ The time that the system takes to return to permanent ${ }^{24}$ condition also depends on wind velocity magnitude, which

${ }^{25}$ means that the greater the disturbance in the system the ${ }^{26}$ more time the system takes to return to permanent ${ }^{27}$ conditions.

28 The behavior of the flow is connected to the ${ }^{29}$ behavior of water depth, which can be seen in Figure 3. As ${ }^{30}$ soon as the wind starts acting, the water depth starts varying ${ }^{31}$ with maximum rate, this rate progressively decreases until it ${ }^{32}$ reaches zero and the water depth reaches a new permanent ${ }^{33}$ value. This occurs in the same time as the flow returns to

${ }^{34}$ the previous value of $1000 \mathrm{~m}^{3} / \mathrm{s}$. It can therefore be ${ }^{35}$ concluded that under continuous and constant wind action, ${ }^{36}$ after enough time, the system converges to a new steady ${ }^{37}$ state balance condition with the same flow and a different ${ }^{38}$ water depth. The wind action can facilitate water flow with ${ }^{39}$ positive velocities causing a decrease in depth, and can dam 40 the water flow with negative velocities causing an increase 41 in depth. As occurs in the flow behavior, the greater the ${ }^{42}$ wind velocity is, the greater is the disturbance in water ${ }^{43}$ depth, which is also greater for negative velocities.

$44 \quad$ Figure 4 shows the longitudinal profiles in 45 different time intervals. In the earlier time intervals, after ${ }^{46}$ wind action starts, curved profiles are formed with greater 47 (smaller) depths upstream and smaller (greater) depths 48 downstream for negative (positive) wind velocities. As time 49 passes the differences of depth in the profile diminish until 50 there are no differences in different sections in the new ${ }^{51}$ steady state balance.

\section{${ }^{53}$ Simulation 2 - Influence of a wind pulse}

$54 \quad$ This simulation intended to verify the influence of 55 continuous and constant wind action on the flow ${ }^{56}$ characteristics considering 6 different wind velocities: -5 ${ }^{57} \mathrm{~m} / \mathrm{s},-10 \mathrm{~m} / \mathrm{s},-15 \mathrm{~m} / \mathrm{s}, 5 \mathrm{~m} / \mathrm{s}, 10 \mathrm{~m} / \mathrm{s}$ and $15 \mathrm{~m} / \mathrm{s}$. Results 58 are shown in figures 5 to 7 . On Figure 7 the upper limit ${ }^{59}$ time interval of the plotted curves was $300 \mathrm{~h}$.

60

61 


\section{Preprint}
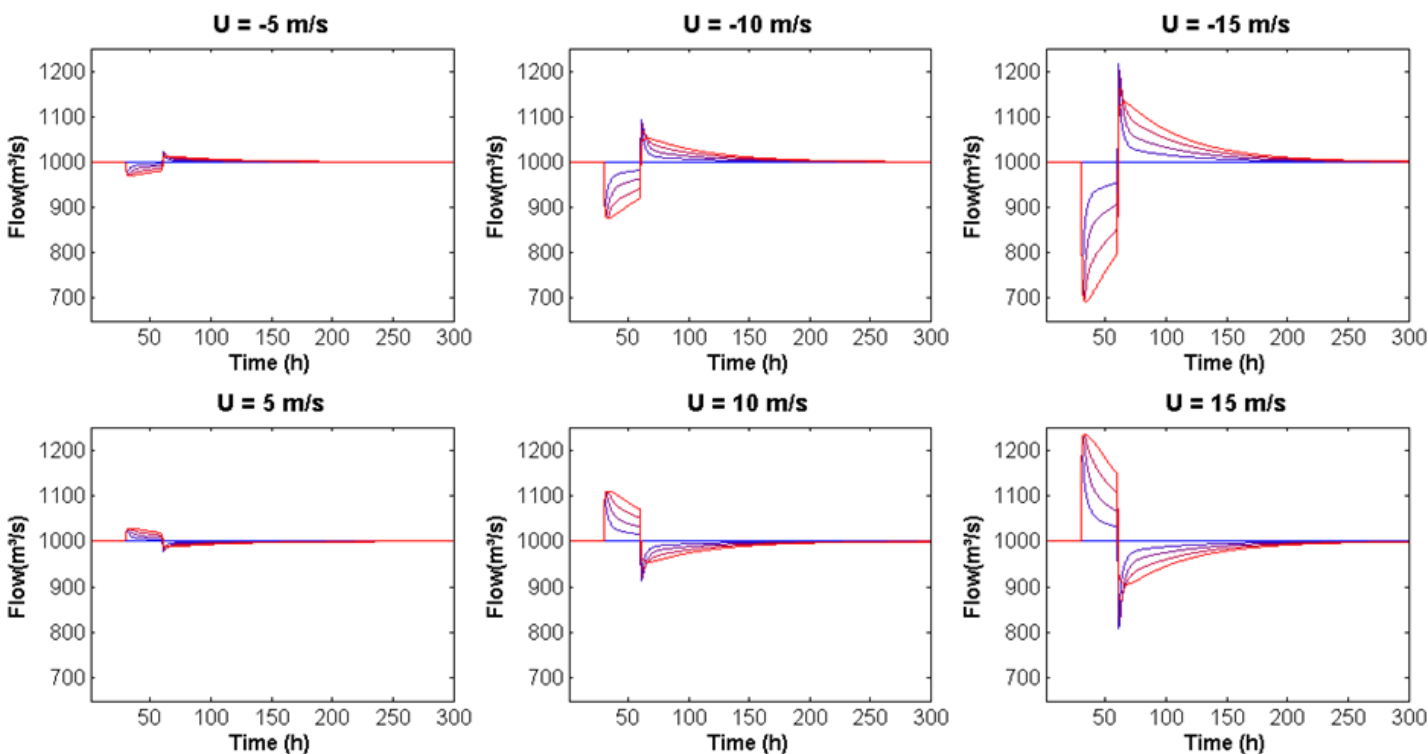

legend $\longrightarrow$ Inflow $-\mathrm{x}=\mathrm{L}^{*} 0.25-\mathrm{x}=\mathrm{L}^{*} 0.50-\mathrm{x}=\mathrm{L}^{\star} 0.75-\mathrm{x}=\mathrm{L}$

Figure 4 - Flow hydrographs under the pulse wind profile influence
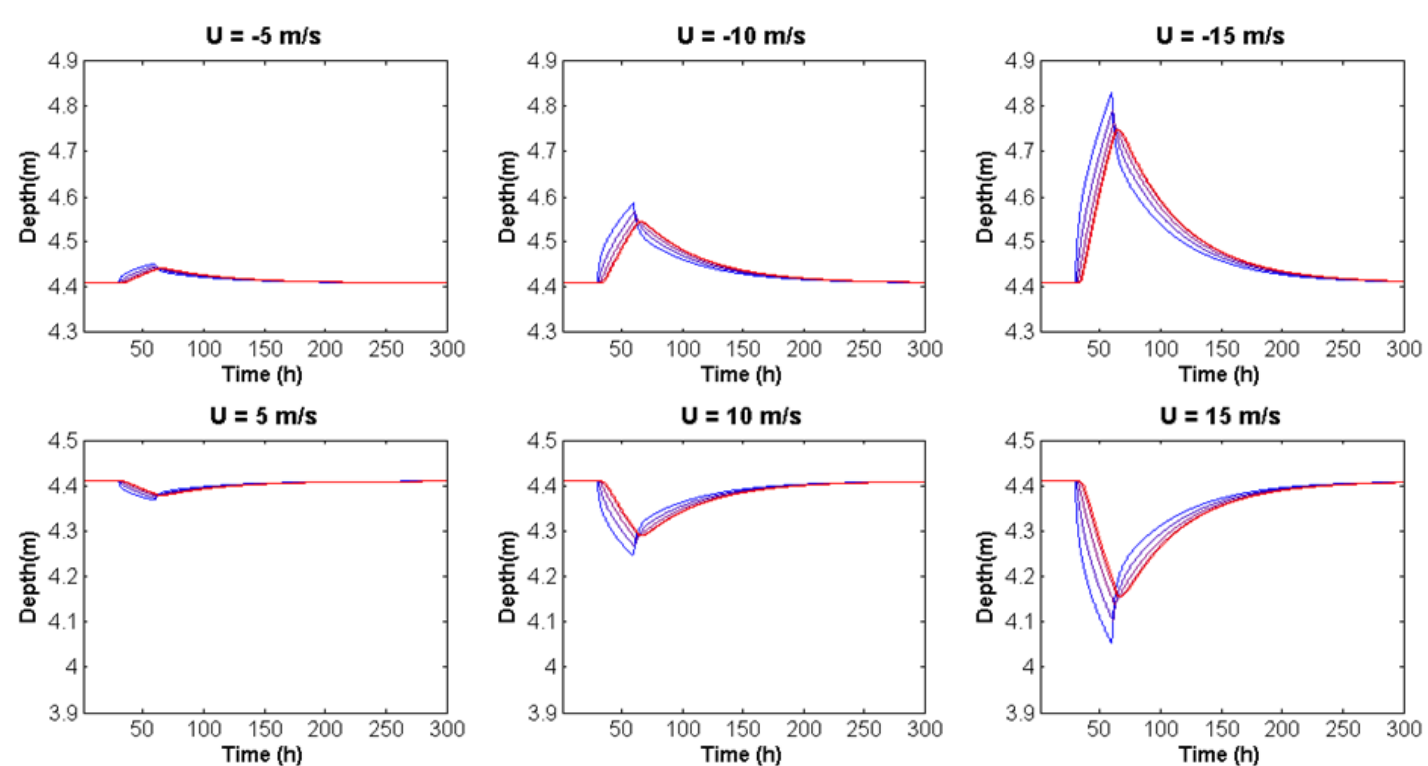

legend $\longrightarrow \mathrm{Inflow} \longrightarrow \mathrm{x}=\mathrm{L}^{*} 0.25-\mathrm{x}=\mathrm{L}^{*} 0.50-\mathrm{x}=\mathrm{L}^{*} 0.75-\mathrm{x}=\mathrm{L}$

Figure 5 - Water depth versus time under the pulse wind profile influence 

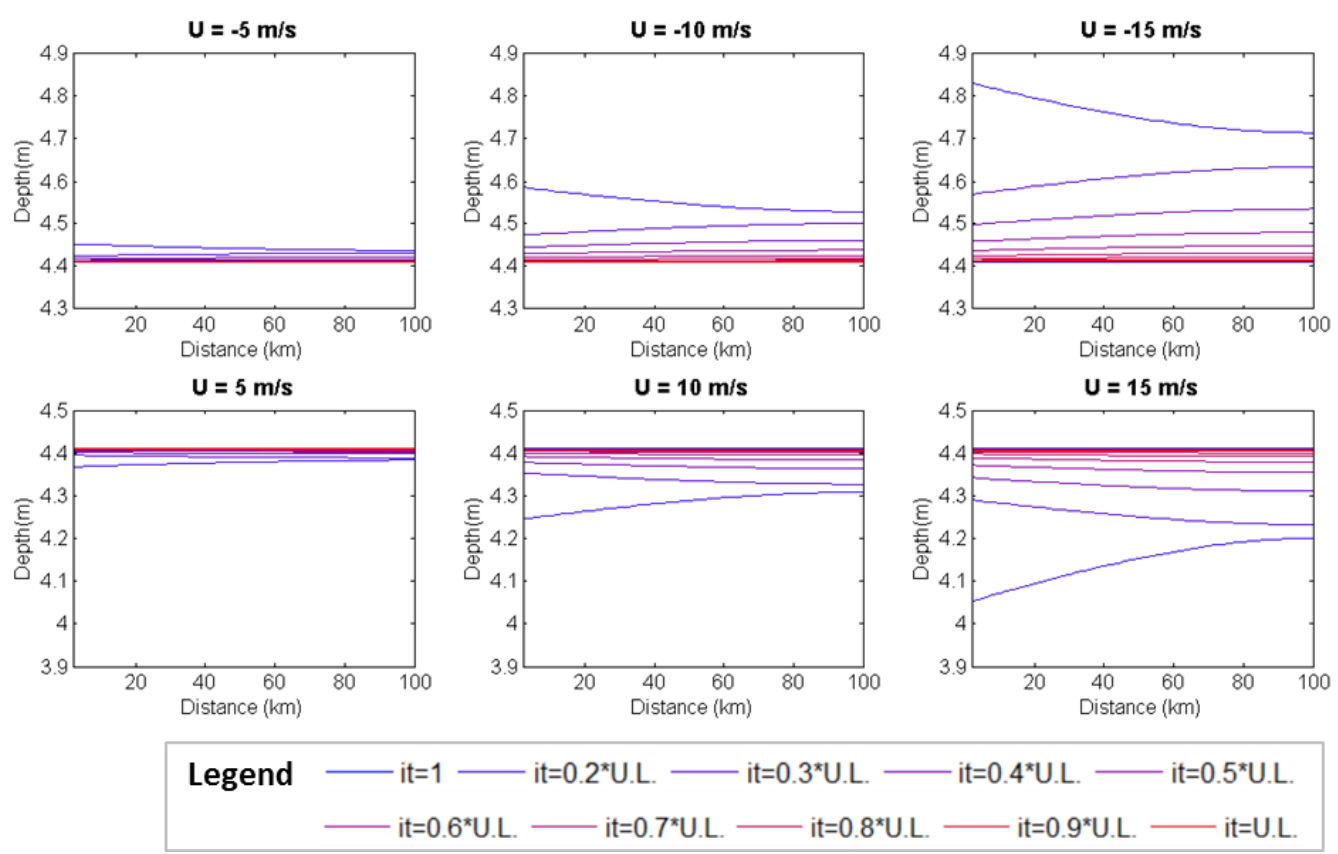

Figure 6 - Water depth longitudinal profiles under the pulse wind profile influence

Until 60 hours of simulation, figures 5, 6 and 7 ${ }^{6}$ show the same behavior as figures 2,3 and 4 . Considering ${ }^{7}$ negative wind velocities, while the wind acts, the flow is ${ }^{8}$ lower than the normal flow and the water depth increases, ${ }^{9}$ creating a curved longitudinal profile with greater water ${ }^{10}$ depths upstream. When the wind stops, all the water that ${ }^{11}$ was piled up ought to leave the system to re-establish the 12 previous permanent equilibrium, which causes an ${ }^{13}$ immediate increase in flow to greater values than the normal 14 flow condition. Additionally, just after the wind stops, a ${ }^{15}$ wave is created by the difference of water level and ${ }^{16}$ propagates downstream. After that, the profile changes, ${ }^{17}$ with smaller depths upstream and greater depths ${ }^{18}$ downstream. As the time passes the differences between ${ }^{19}$ upstream and downstream water levels diminishes as well as ${ }^{20}$ the value of mean water level. This happens until there are ${ }^{21}$ no differences of water depth in the longitudinal profile and 22 the depth reach the previous condition. The contrary occurs ${ }^{23}$ considering positive velocities.
24 ${ }^{25} 6$, the dislocation of water level peaks (positive or negative), ${ }^{26}$ which happen before in upstream sessions. In addition, ${ }^{27}$ downstream, the peeks are less sharp and with lesser ${ }^{28}$ magnitude than upstream.

29

\section{${ }^{30}$ Simulation 3 - Influence of reach length}

31 This simulation was performed with the objective ${ }^{32}$ to verify the influence of the hypothetical reach length on ${ }^{33}$ the flow response to wind action $(-15 \mathrm{~m} / \mathrm{s})$ and on the ${ }^{34}$ influence of the upstream boundary condition. The lengths ${ }^{35}$ of $25 \mathrm{~km}, 50 \mathrm{~km}$ and $100 \mathrm{~km}$ were compared considering ${ }^{36}$ both continuous and pulse wind profiles. Results are ${ }^{37}$ displayed in figures 8 and 9 , considering a continuous wind ${ }^{38}$ profile, and in figures 10 and 11 , considering a pulse wind ${ }^{39}$ profile.

40

41 

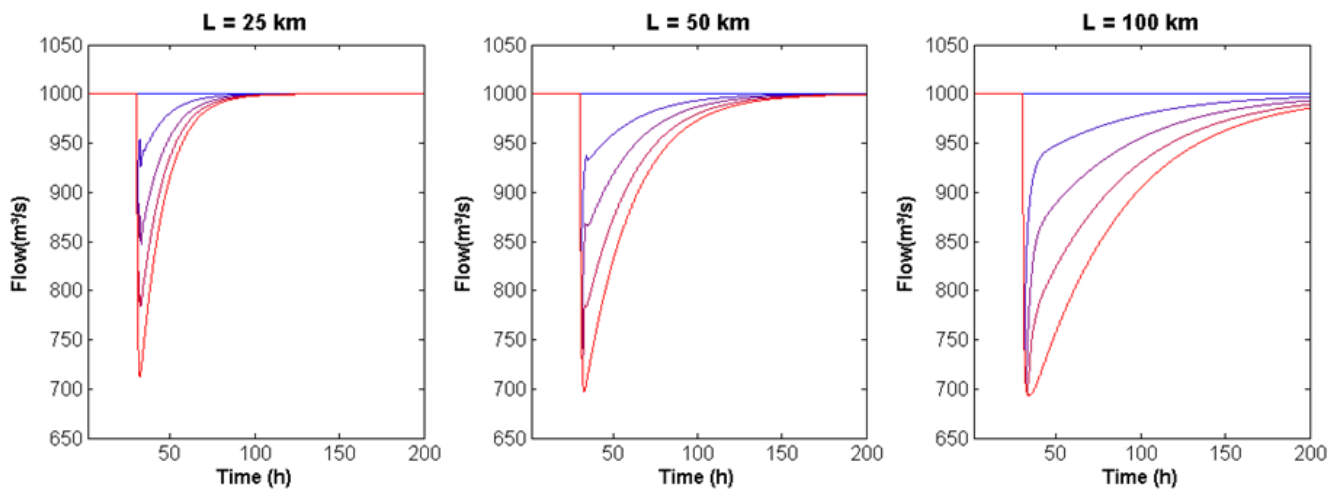

legend $\longrightarrow \mathrm{Inflow}-\mathrm{x}=\mathrm{L}^{*} 0.25-\mathrm{x}=\mathrm{L}^{*} 0.50-\mathrm{x}=\mathrm{L}^{*} 0.75-\mathrm{x}=\mathrm{L}$

Figure 7 - Flow hydrographs under continuous wind influence for different reach lengths and $U=-15 \mathrm{~m} / \mathrm{s}$.
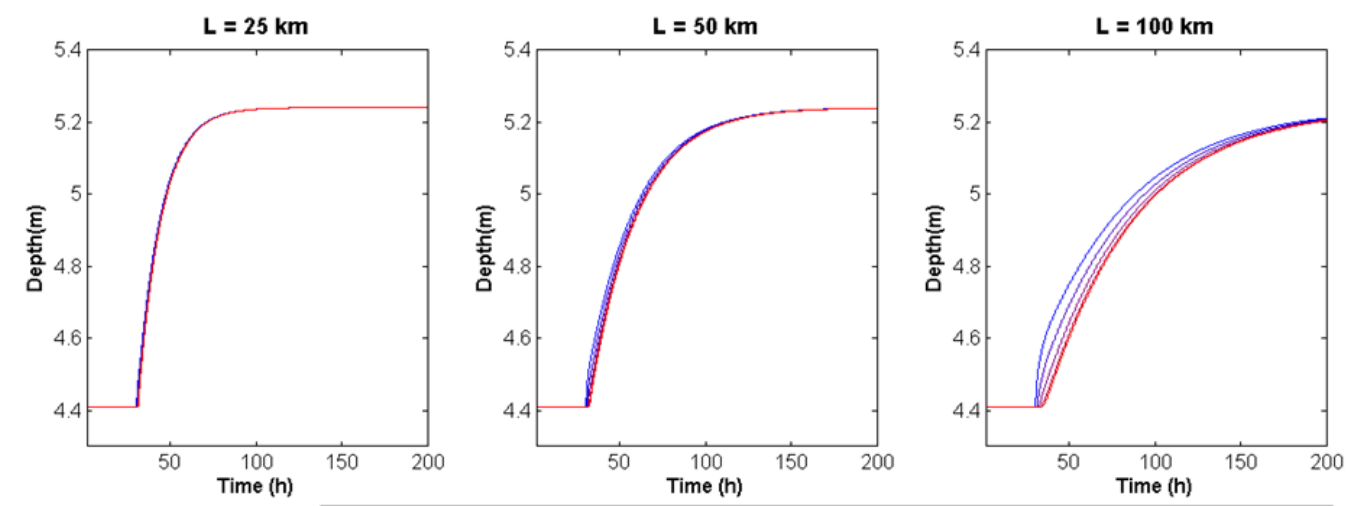

legend $\longrightarrow$ Inflow $-\mathrm{x}=\mathrm{L}^{*} 0.25-\mathrm{x}=\mathrm{L}^{*} 0.50-\mathrm{x}=\mathrm{L}^{*} 0.75-\mathrm{x}=\mathrm{L}$

Figure 8 - Water depth versus time under continuous wind influence for different reach lengths and $U=-15 \mathrm{~m} / \mathrm{s}$.
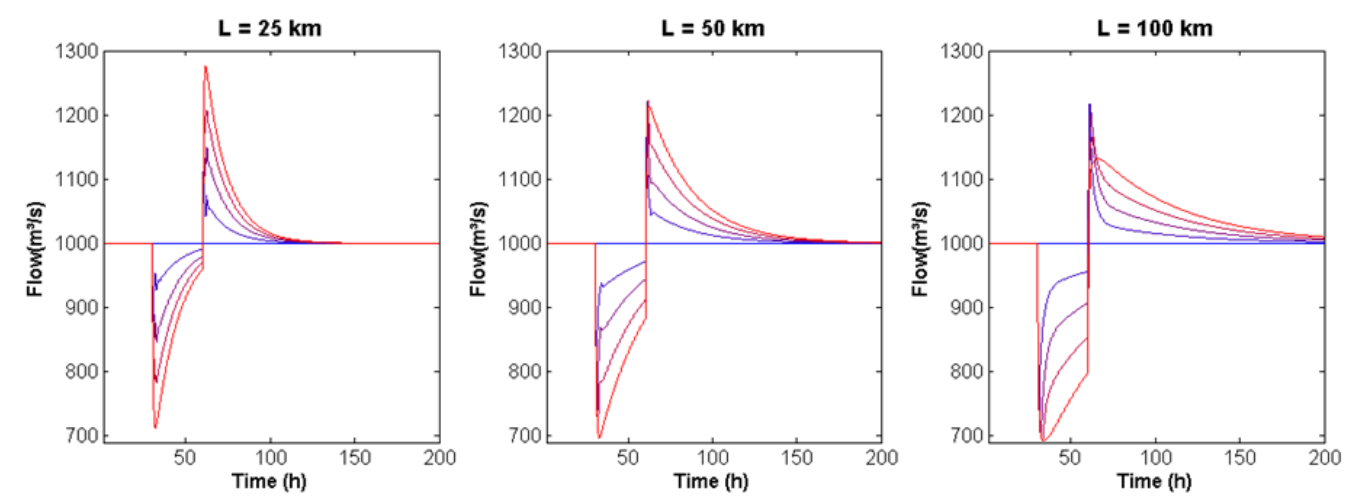

legend $\longrightarrow$ Inflow $-\mathrm{x}=\mathrm{L}^{*} 0.25-\mathrm{x}=\mathrm{L}^{*} 0.50-\mathrm{x}=\mathrm{L}^{*} 0.75-\mathrm{x}=\mathrm{L}$

Figure 9 - Flow hydrographs under the pulse wind profile influence for different reach lengths and $U=-15 \mathrm{~m} / \mathrm{s}$. 

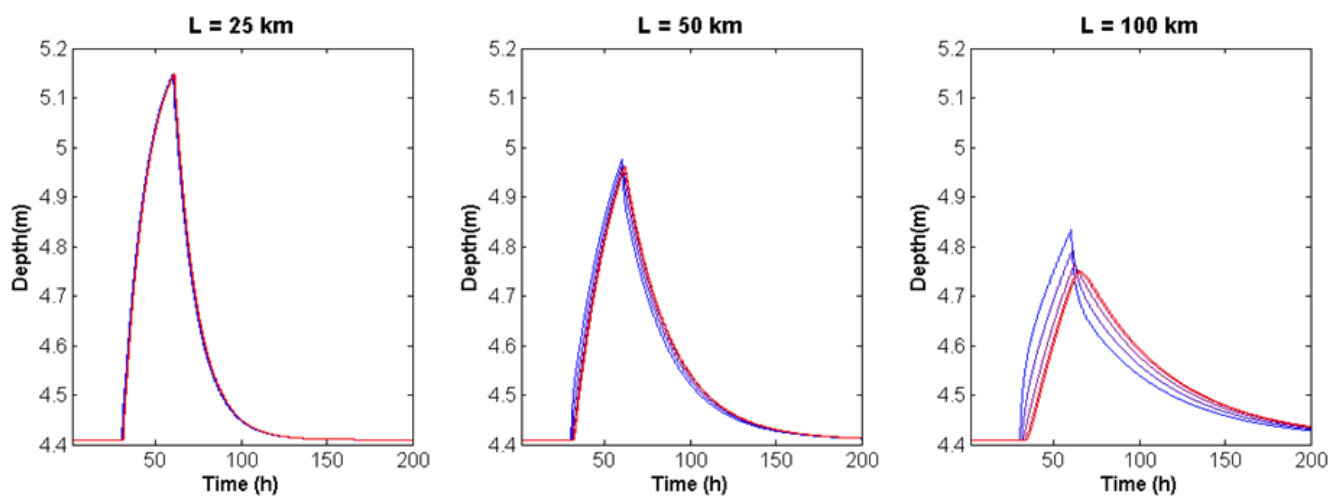

legend $\longrightarrow \mathrm{Inflow}-\mathrm{x}=\mathrm{L}^{*} 0.25-\mathrm{x}=\mathrm{L}^{*} 0.50-\mathrm{x}=\mathrm{L}^{*} 0.75-\mathrm{x}=\mathrm{L}$

Figure 10 - Water depth versus time under the pulse wind profile influence for different reach lengths and $\mathrm{U}=-15 \mathrm{~m} / \mathrm{s}$.

Analyzing figures 8 and 9 one can verify that small 5 oscillations in flow occur considering shorter reach lengths.

${ }^{6}$ This can be explained by the reflection of flow variations on

7 the boundary conditions, which propagate downstream and

${ }^{8}$ upstream until they are dissipated. The correspondent water

${ }^{9}$ depth variations are too small to be seen on the figures.

10

The longer the reach is, the longer it takes for a ${ }^{11}$ new equilibrium condition to be stablished. E.g. for a $25 \mathrm{~km}$

12 reach, after the wind starts blowing, it takes approximately

${ }^{13} 70 \mathrm{~h}$ for the system to reach equilibrium, for $50 \mathrm{~km}$, the

${ }^{14}$ period is approximately $140 \mathrm{~h}$ and for $100 \mathrm{~km}$ it takes 220

${ }^{15} \mathrm{~h}$. This is related to the fact that there is more water in the

${ }^{16}$ system to pile up for longer reaches, because continuous

${ }^{17}$ wind action changes de water storage in the system and the

${ }^{18}$ water storage absolute variation due to continuous wind

${ }^{19}$ action is greater for longer reaches.

20 From figures 10 and 11 one can notice that in ${ }^{21}$ response to the longer times required by longer reaches to

22 reach equilibrium under continuous wind influence, the
${ }^{23}$ time for the system to return to previous conditions under ${ }^{24}$ the pulse profile is also longer. Hence, when considering ${ }^{25}$ wind influence over large systems, there has to be noted that ${ }^{26}$ this influence may last much longer than the wind action ${ }^{27}$ period due to the inertia of the system.

28 Considering longer reaches, flow hydrographs and ${ }^{29}$ water depth variations with time are smother and take larger ${ }^{30}$ periods to propagate downstream.

\section{${ }^{32}$ Simulation 4 - Influence of inflows}

${ }_{33}$ This simulation was performed to assess the 34 influence of continuous wind $(-10 \mathrm{~m} / \mathrm{s})$ in the flow ${ }^{35}$ considering different inflow values. The inflows values of ${ }^{36} 100 \mathrm{~m}^{3} / \mathrm{s}, 1000 \mathrm{~m}^{3} / \mathrm{s}$ and $5000 \mathrm{~m}^{3} / \mathrm{s}$ were selected to ${ }^{37}$ correspond to low flow, average flow, and high flow periods ${ }^{38}$ usually observed in the Jacuí River. Results are presented in ${ }^{39}$ figures 12 and 13.
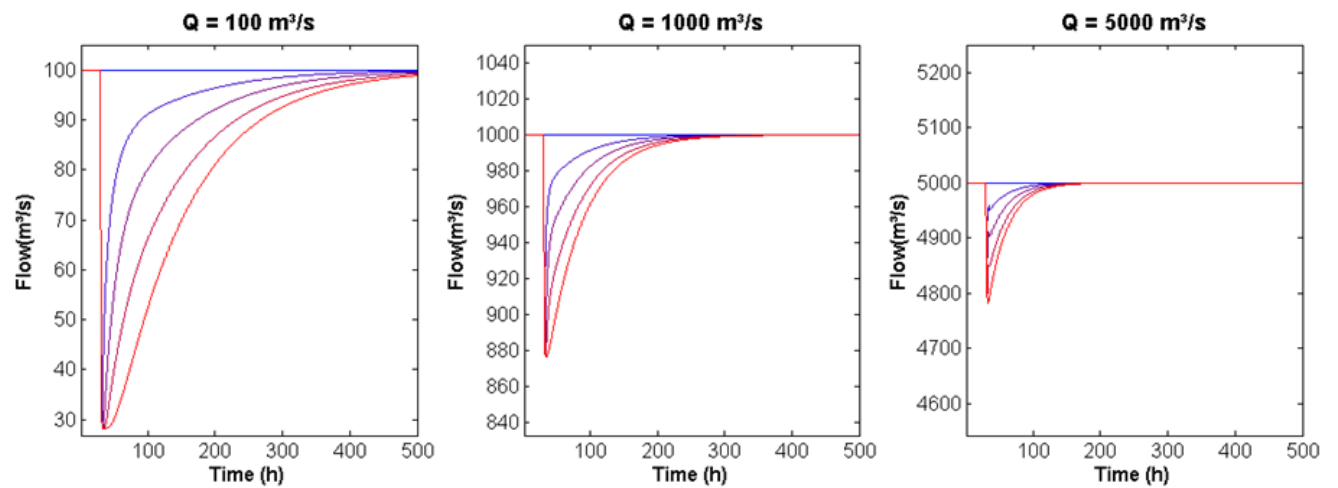

legend

Time (h)

Time (h)

Figure 11 - Flow hydrographs under continuous wind influence for different inflow values and U=-10 m/s. 

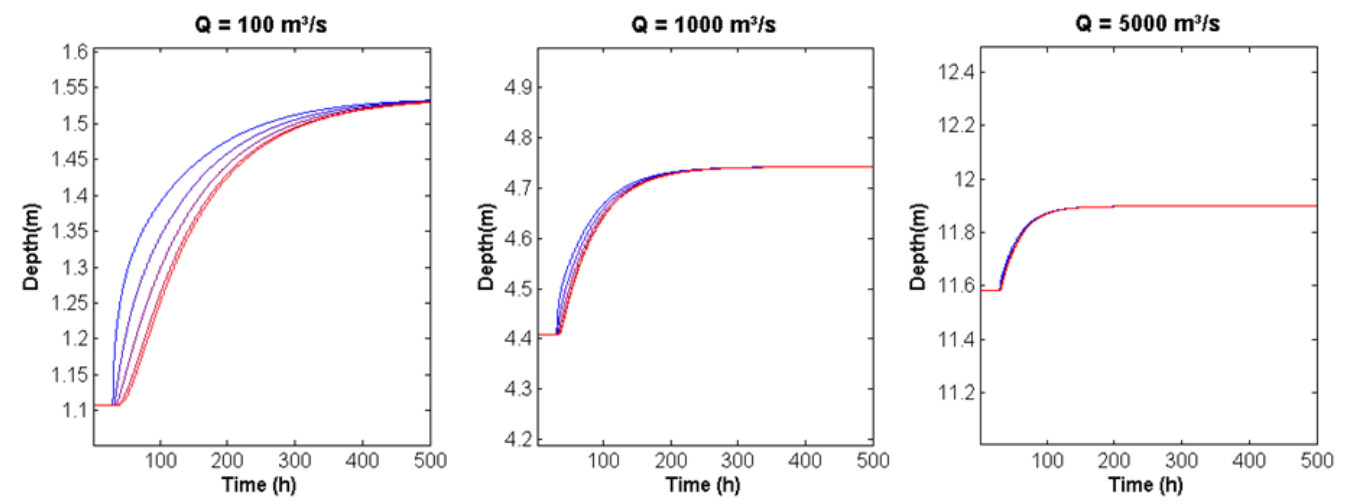

legend - Inflow $-\mathrm{x}=\mathrm{L}^{*} 0.25-\mathrm{x}=\mathrm{L}^{*} 0.50-\mathrm{x}=\mathrm{L}^{*} 0.75-\mathrm{x}=\mathrm{L}$ 6 absolute variation of flow is greater for higher inflow ${ }^{7}$ conditions, however the associated relative variation ${ }^{8}$ considerably is lower. E.g. for an inflow of $100 \mathrm{~m}^{3} / \mathrm{s}$ the ${ }^{9}$ maximum flow variation is approximately $70 \mathrm{~m}^{3} / \mathrm{s}$ which ${ }^{10}$ corresponds to a decrease of $70 \%$. Considering an inflow of $115000 \mathrm{~m}^{3} / \mathrm{s}$, the variation is approximately $200 \mathrm{~m}^{3} / \mathrm{s}$ 12 representing a decrease of flow of only $4 \%$.

13 The influence of boundary conditions, manifested 14 through small flow oscillations in early periods after wind 15 incidence started, can be perceived for the inflow value of $165000 \mathrm{~m}^{3} / \mathrm{s}$. This is probably related to the higher water ${ }^{17}$ velocity under this condition which makes the variations of 18 flow, although relatively smaller, to propagate more rapidly 19 (i.e. with greater celerity). This can be attested by the ${ }^{20}$ decrease of these oscillations using larger reach widths. E.g. ${ }^{21}$ Considering the same conditions but a river width of 2000 ${ }^{22} \mathrm{~m}$, although resulting in larger flow disturbance due to wind 23 action, these flow oscillations do not occur.
${ }^{26}$ related to previous conditions. For example, considering an 27 inflow of $100 \mathrm{~m}^{3} / \mathrm{s}$, the depth variation reaches $40 \mathrm{~cm}$ which ${ }^{28}$ corresponds to an increase of depth of approximately $36 \%$; ${ }^{29}$ considering $5000 \mathrm{~m}^{3} / \mathrm{s}$ of inflow this variation is ${ }^{30}$ approximately $30 \mathrm{~cm}$ and corresponds to an increase of ${ }^{31}$ depth of only $2.6 \%$.

32 Once more, greater disturbance in flow conditions ${ }^{33}$ due to wind stress is related to longer periods to reach the ${ }^{34}$ new state of equilibrium.

\section{${ }^{36}$ Simulation 5 - Influence of bed slope}

37 Simulation 5 was performed to assess the influence 38 of bed slope on flow characteristics under continuous wind ${ }^{39}$ stress $(-10 \mathrm{~m} / \mathrm{s})$. The values of $50 \mathrm{~m} / \mathrm{km}, 5 \mathrm{~m} / \mathrm{km}, 0.5$ ${ }^{40} \mathrm{~m} / \mathrm{km}, 5 \times 10^{-2} \mathrm{~m} / \mathrm{km}, 5 \times 10^{-3} \mathrm{~m} / \mathrm{km}$ e $5 \times 10^{-4} \mathrm{~m} / \mathrm{km}$ were ${ }^{41}$ tested. These values were selected to comprehend very steep 42 and very flat scenarios. For this simulation a smaller value ${ }^{43}$ of $\alpha(0.01)$ was necessary to simulate steep slopes with no ${ }^{44}$ numerical instability. Results are displayed in figures 14 and 4515 .

46 47 

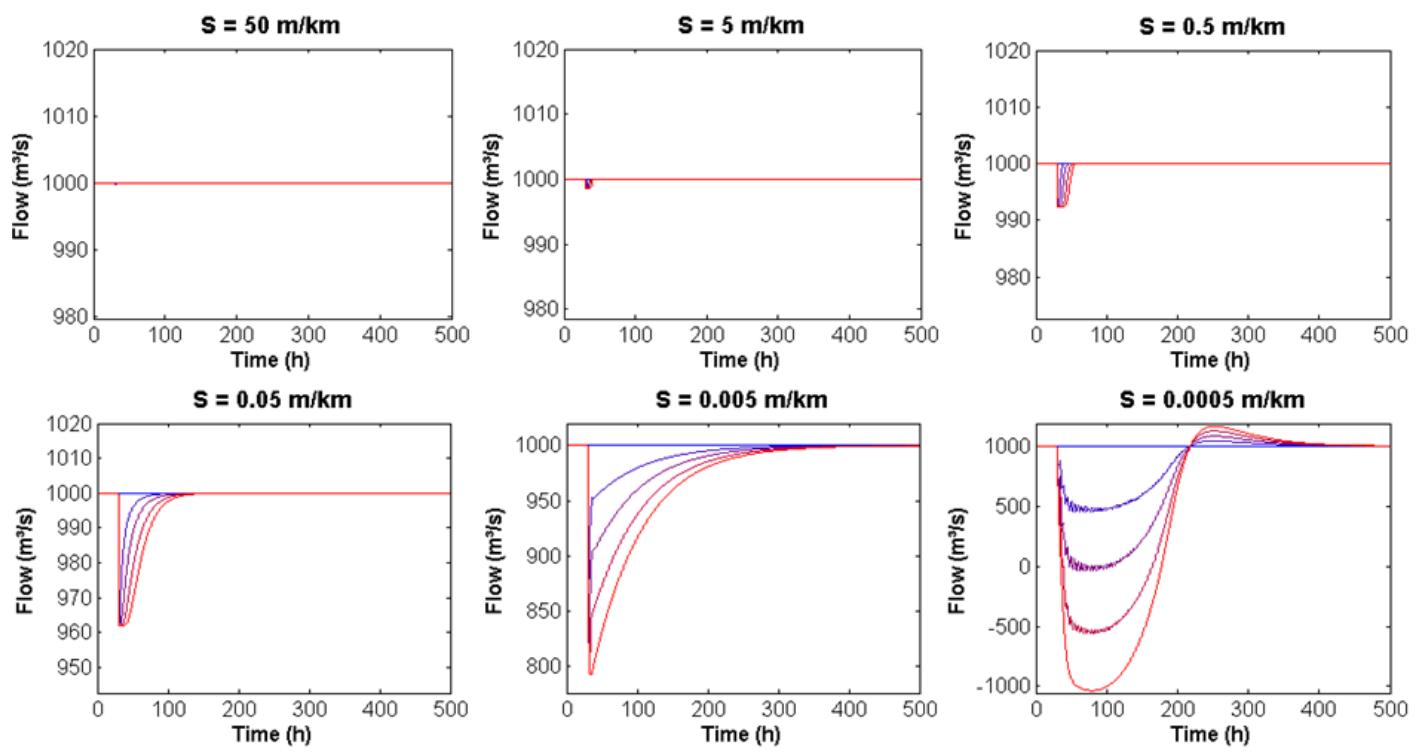

legend $\longrightarrow$ Inflow $-\mathrm{x}=\mathrm{L}^{*} 0.25-\mathrm{x}=\mathrm{L}^{*} 0.50-\mathrm{x}=\mathrm{L}^{*} 0.75-\mathrm{x}=\mathrm{L}$

Figure 13 - Flow hydrographs under continuous wind influence for different bed slope (S) values and U=-10 m/s.
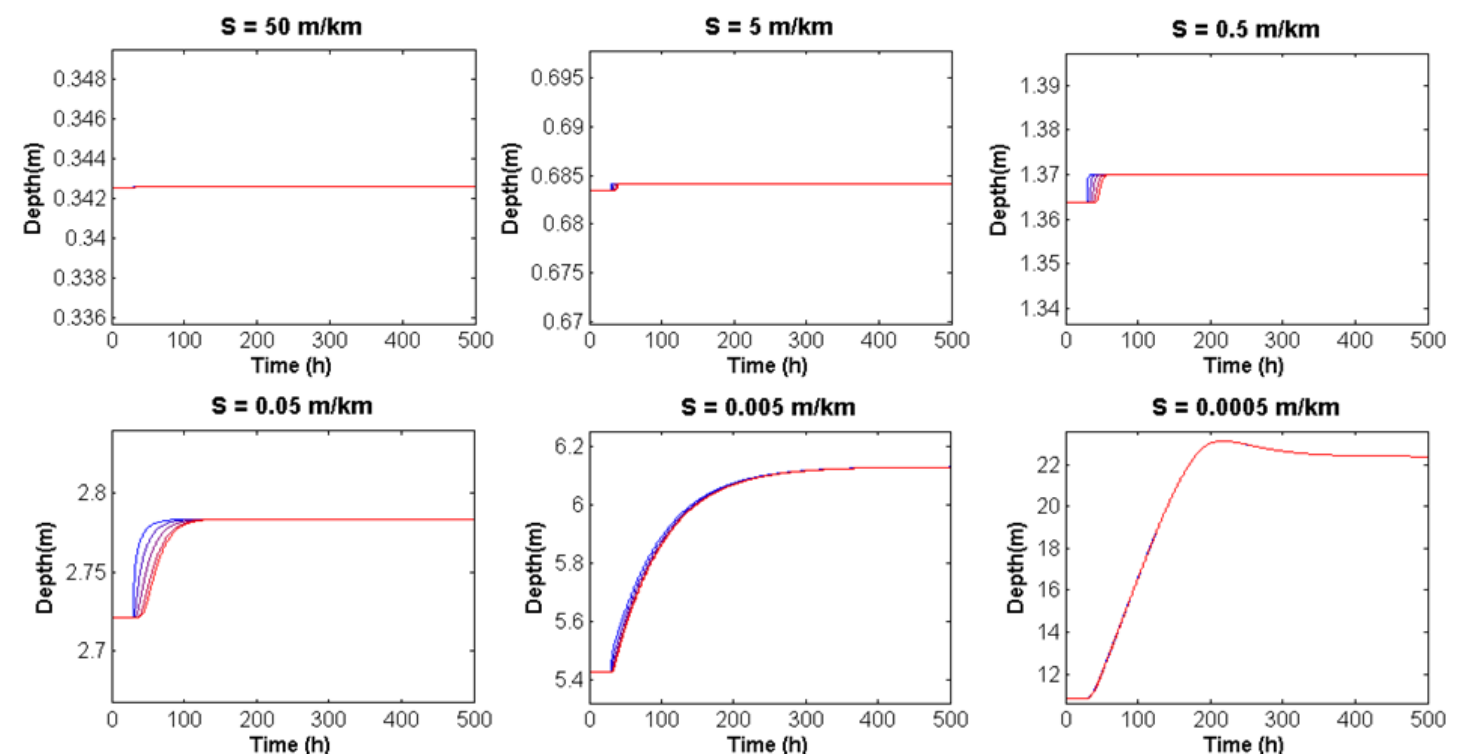

legend $\longrightarrow$ Inflow $-\mathrm{x}=\mathrm{L}^{*} 0.25-\mathrm{x}=\mathrm{L}^{*} 0.50-\mathrm{x}=\mathrm{L}^{*} 0.75-\mathrm{x}=\mathrm{L}$

5 Figure 14 - Water depth versus time Flow under continuous wind influence for different bed slope (S) values and U=-10 m/s.

From the analysis of figures 14 and 15 it can be ${ }^{9}$ noted that wind effect is greater for lower bed slope ${ }^{10}$ configurations. Considering bed slope values equal or ${ }^{11}$ greater than $0.5 \mathrm{~m} / \mathrm{km}$, the variations in depth are not 12 significant. Considering the slope of $0.05 \mathrm{~m} / \mathrm{km}$, the ${ }^{13}$ variation is only $6 \mathrm{~cm}$, which corresponds to an increase of 14 approximately $2 \%$ of water depth and a decrease of ${ }^{15}$ approximately $4 \%$ of flow.
16 Considering a slope of $5 \times 10^{-3} \mathrm{~m} / \mathrm{km}$, the increase 17 in depth is much greater, achieving an absolute variation of ${ }^{18}$ approximately $70 \mathrm{~cm}$ and an increase of $13 \%$. The decrease 19 of flow in this case was approximately $20 \%$. Small ${ }^{20}$ oscillations were apparent in the flow hydrograph, which are ${ }^{21}$ not only related to the flow celerity, but especially to the ${ }^{22}$ magnitude of the disturbance caused by the wind action. ${ }^{23}$ These oscillations do not occur with a wind velocity of -5 ${ }^{24} \mathrm{~m} / \mathrm{s}$. 


\section{Preprint}

Considering the slope of $5 \times 10^{-4} \mathrm{~m} / \mathrm{km}$, which is an ${ }^{2}$ unmeasurable flat slope very difficult to be found in riverine ${ }^{3}$ natural environments, a particular behavior can be noticed.

${ }^{4}$ Under this hypothetical extremely flat condition, the wind

${ }^{5}$ shows a major influence in flow characteristics. The water

${ }^{6}$ depth increases $120 \%$ in the new equilibrium and the flow

${ }^{7}$ reaches negative values decreasing over 200\%. The

8 influence of the wind is strong enough to cause an increase

${ }^{9}$ in depth greater than the increase associated to the new

${ }^{10}$ equilibrium, which causes a flow wave to propagate with

${ }^{11}$ associated increase in flow to greater values than the inflow.

${ }^{12}$ Many oscillations occur in this case due to the susceptibility

${ }^{13}$ of the system to wind influence. These are also potentialized

${ }^{14}$ by the establishment of negative flows that compete with

${ }^{15}$ the positive inflows. Oscillations considering these
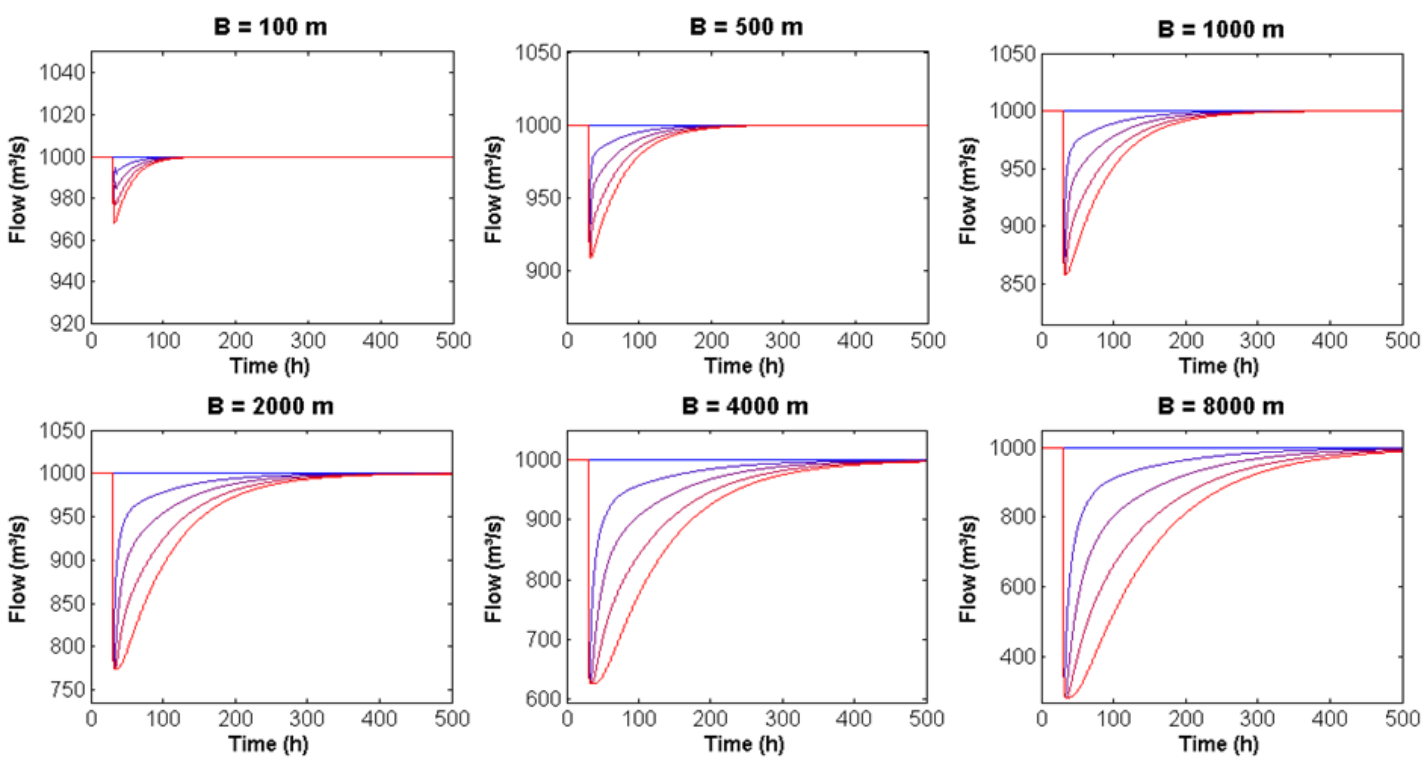

legend
${ }^{16}$ characteristics still occur even for very small wind velocities.

17 This is probably related to the very small bottom slope

${ }^{18}$ which allows oscillations to propagate in both directions

${ }^{19}$ with low dissipation of their energy.

\section{${ }^{21}$ Simulation 6 - Influence of river width}

This simulation was performed to assess the

${ }^{23}$ influence of river width under constant wind stress (-10

$\left.{ }^{24} \mathrm{~m} / \mathrm{s}\right)$. The widths of $100 \mathrm{~m}, 500 \mathrm{~m}, 1000 \mathrm{~m}, 2000 \mathrm{~m}, 4000$

${ }^{25} \mathrm{~m}$ and $8000 \mathrm{~m}$ were tested to comprehend a wide variety of

${ }^{26}$ scenarios. Results are displayed in figures 16 and 17.

28

Figure 15 - Flow hydrographs under continuous wind influence for different reach width (B) values and $U=-10 \mathrm{~m} / \mathrm{s}$. 

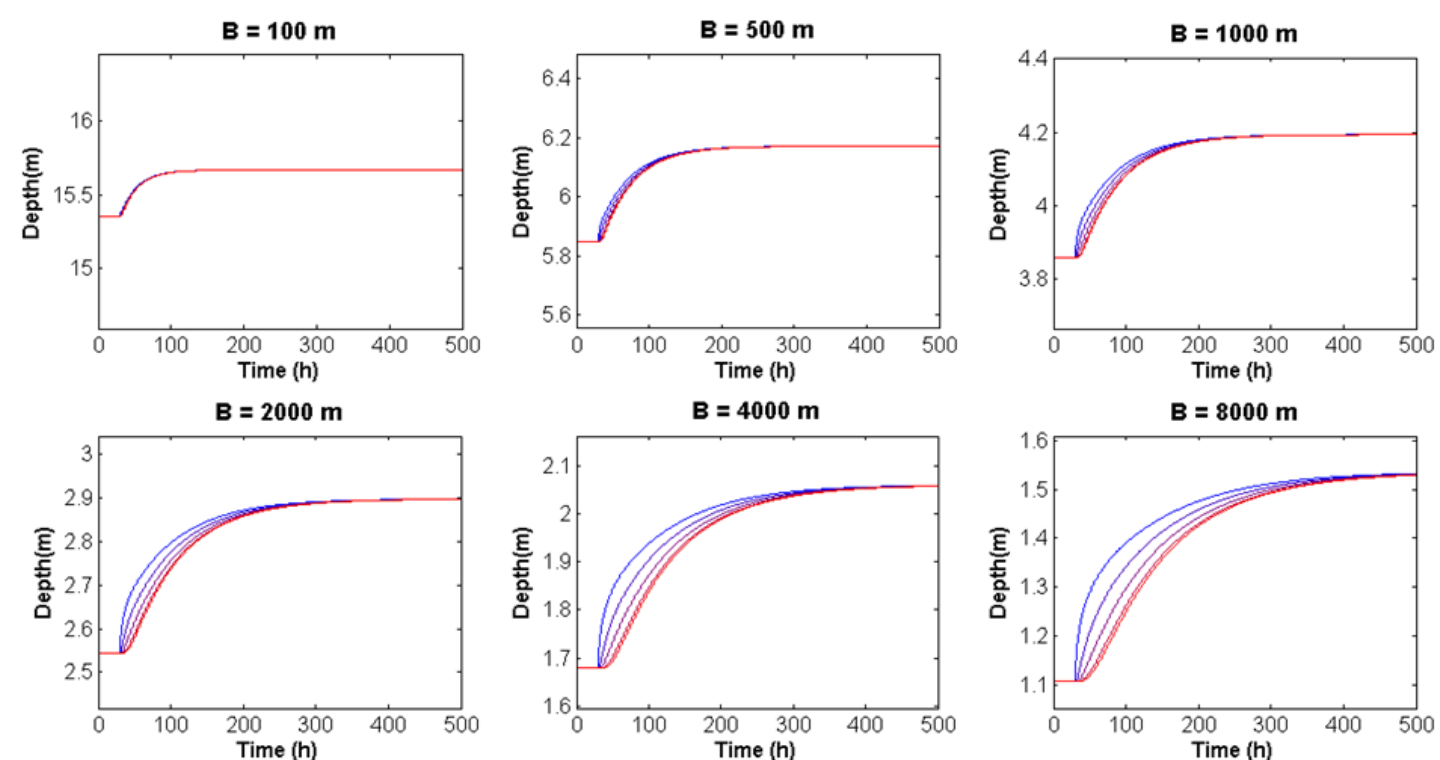

legend $\longrightarrow$ Inflow $-\mathrm{x}=\mathrm{L}^{*} 0.25-\mathrm{x}=\mathrm{L}^{*} 0.50-\mathrm{x}=\mathrm{L}^{*} 0.75-\mathrm{x}=\mathrm{L}$

Figure 16 - Water depth versus time Flow under continuous wind influence for different reach width (B) values and U=-10 $\mathrm{m} / \mathrm{s}$.

Through the analysis of figures 16 and 17 , it was ${ }^{7}$ observed that simulations considering larger widths result in ${ }^{8}$ greater variations of flow conditions due to wind effect. E. ${ }^{9} \mathrm{~g}$. considering a width value of $100 \mathrm{~m}$, the water depth ${ }^{10}$ variation is $30 \mathrm{~cm}$ corresponding to an increase of $2 \%$; for ${ }^{11}$ the value of width of $8000 \mathrm{~m}$ the variation reaches ${ }^{12}$ approximately $42 \mathrm{~cm}$, corresponding to an increase of $40 \%$. ${ }^{13}$ Small oscillations can be noticed for the width of $100 \mathrm{~m}$, due ${ }^{14}$ to the effect of the greater celerity of this scenario.

15

27
${ }^{16}$ Simulation 7 - Influence of the wind friction ${ }^{17}$ coefficient

18 The objective of simulation 7 was to assess the 19 influence of the wind friction coefficient under constant ${ }^{20}$ wind stress $(-10 \mathrm{~m} / \mathrm{s})$. The coefficients of $0.5 \times 10^{-6}, 1.0 \times 10^{-6}$, ${ }^{21} 1.5 \times 10^{-6}, 2.0 \times 10^{-6}, 3.0 \times 10^{-6}, 4.0 \times 10^{-6}$, were tested to 22 comprehend a wide variety of scenarios. Values as large as ${ }^{23} 4.0 \times 10^{-6}$ were reported in literature (PAZ et al., 2005; WU, 24 1982). 

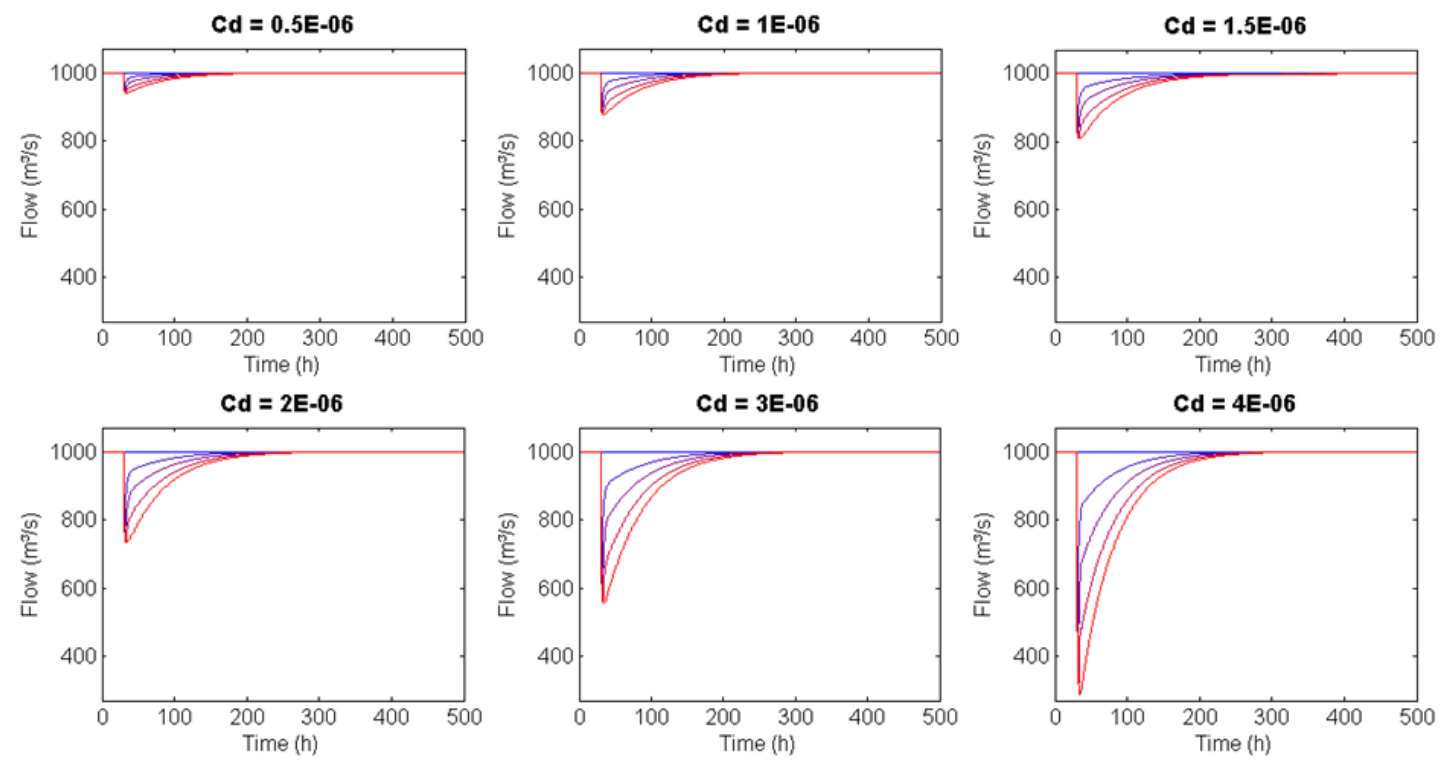

legend

Inflow $-\mathrm{x}=\mathrm{L}^{*} 0.25-\mathrm{x}=\mathrm{L}^{*} 0.50-\mathrm{x}=\mathrm{L}^{*} 0.75-\mathrm{x}=\mathrm{L}$

Figure 17 - Flow hydrographs under continuous wind influence for different $C D$ values and $U=-10 \mathrm{~m} / \mathrm{s}$.
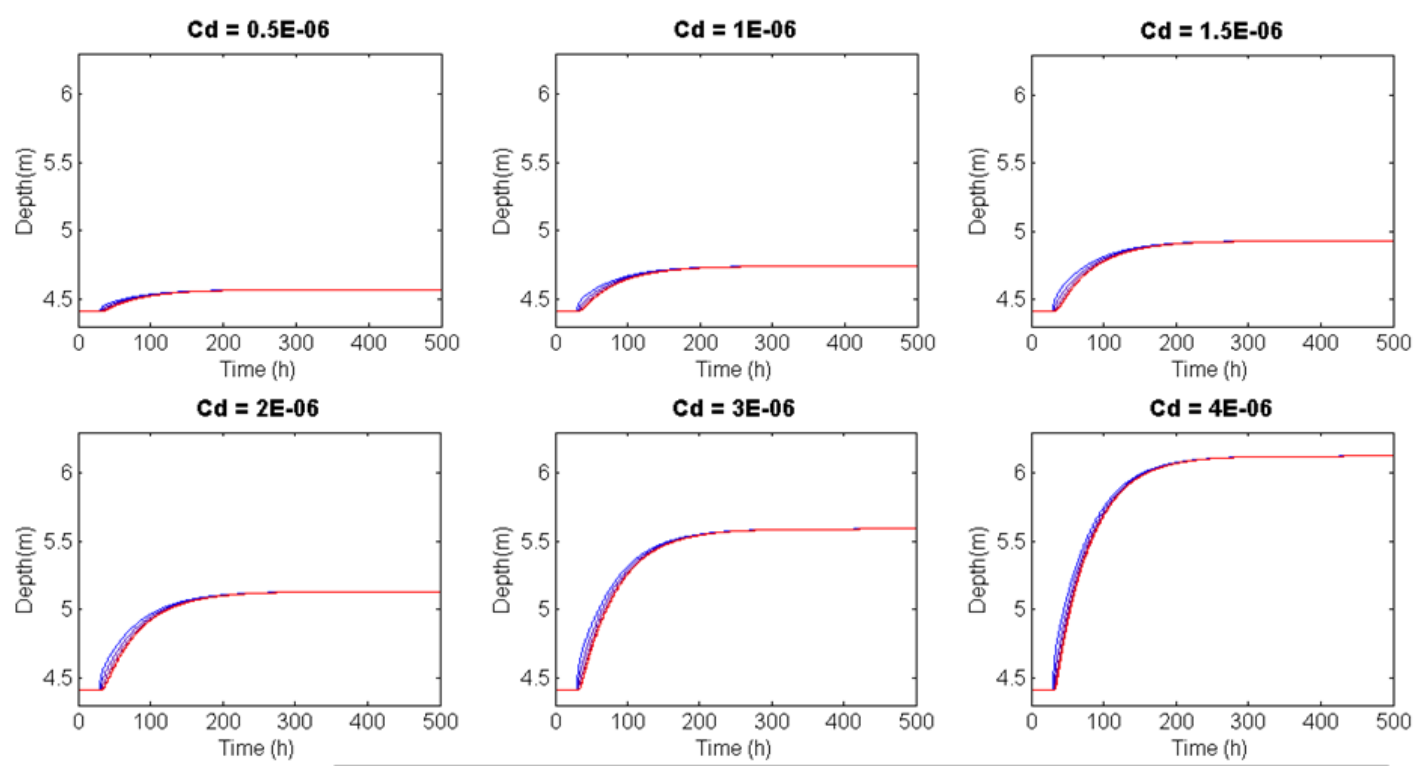

legend

$$
\longrightarrow \mathrm{Inflow}-\mathrm{x}=\mathrm{L}^{*} 0.25-\mathrm{x}=\mathrm{L}^{*} 0.50-\mathrm{x}=\mathrm{L}^{*} 0.75-\mathrm{x}=\mathrm{L}
$$

Figure 18 - Water depth versus time Flow under continuous wind influence for different $C D$ values and $U=-10 \mathrm{~m} / \mathrm{s}$.

This simulation was performed to provide 10 insight over the influence of $C_{D}$ values on the effect ${ }^{11}$ that wind exerts over the flow. It can be seen on ${ }^{12}$ figures 18 and 19 that the disturbance cause by wind ${ }^{13}$ action is greater for greater $C_{D}$ values and therefore
14 that this is an important parameter when modelling ${ }^{15}$ wind influence over hydrodynamic systems.

16 Additionally, the influence of $C_{D}$ values is ${ }^{17}$ greater for greater wind velocities. For example, ${ }^{18}$ considering a wind velocity of $-10 \mathrm{~m} / \mathrm{s}$, the increase in ${ }^{19}$ depth relative variation with a $C_{D}$ equal to $2 \times 10^{-6}$ 
${ }^{1}$ compared to using a value of $4 \times 10^{-6}$, was $100 \%$.

${ }^{2}$ When a value of wind velocity of $-15 \mathrm{~m} / \mathrm{s}$ was

${ }^{3}$ considered, this increase was $167 \%$.

$4 \quad$ It is important to note that numerical

${ }^{5}$ instability was observed for $C_{D}$ values of $3 \times 10^{-6}$ and

${ }^{6} 4 \times 10^{-6}$ using wind velocity of $-15 \mathrm{~m} / \mathrm{s}$, which was

${ }^{7}$ corrected by the use of a $\alpha$ value of 0.5 . This means

${ }^{8}$ that selecting the $\alpha$ value may be necessary to prevent

${ }^{9}$ too elevated time-steps and avoid numerical

${ }^{10}$ instability, especially under extreme wind velocity

${ }^{11}$ conditions.

12

${ }^{13}$ STAGE 2: MAXIMUM DEPTH VARIATION ${ }^{14}$ DUE TO CONTINUOUS WIND INFLUENCE

15

16 As a result of simulations performed with the

${ }^{17}$ local inertial method with wind influence in

${ }^{18}$ hypothetical river flows, new steady state conditions

${ }^{19}$ were found after prolonged constant wind action.

${ }^{20}$ Considering uniform and permanent flow conditions,

${ }^{21}$ under continuous wind action, in the first moments

22 the flow is altered. However, as time passes, the flow

${ }^{23}$ converges back to the previous permanent flow value

${ }^{24}$ and the alteration due to wind effect is perceived in

${ }^{25}$ water depth, which converges to a new value. The

${ }^{26}$ resultant depth value is also constant along the

${ }^{27}$ channel length.

28

The observed behavior allowed us to simplify

${ }^{29}$ Equation 4 to calculate the maximum variation of

${ }^{30}$ depth due to wind influence regarding flows with

${ }^{31}$ different pre-established characteristics. The equation

${ }^{32}$ was simplified considering 2 main assumptions: (i) in

${ }^{33}$ the new equilibrium state the flow is permanent,

${ }^{34}$ which means that the flow does not change with

${ }^{35}$ time. Therefore, the first term of equation 4 can be

${ }^{36}$ neglected; (ii) in the new equilibrium state, the depth

${ }^{37}$ does not change with space; hence, the second term

${ }^{38}$ of Equation 4 can also be neglected.

39

Equation 4 can be re-written as:

40

${ }^{41}-g \cdot A \cdot S_{o}+$ g.A. $S_{f}-B \cdot C_{D} \cdot|U| \cdot U=0$

42

$43 \quad$ Considering that the $S_{f}$ term can be

${ }^{44}$ approximated by the Manning equation and that the
${ }^{45}$ channel is rectangular with width much larger than

${ }^{46}$ depth, Equation 9 can be re-arranged:

47

${ }^{48} h_{w}=\left(\frac{q \cdot|q| \cdot n^{2}}{h_{w}^{7 / 3}}-\frac{C_{D} \cdot U \cdot|U|}{g}\right) \cdot \frac{1}{S}$

49

$50 \quad$ Equation 10 must be solved iteratively to

${ }^{51}$ calculate $h_{w}$, which is the new depth due to

${ }^{52}$ continuous wind effect $(\mathrm{m}) . S$ is the river bottom

${ }^{53}$ slope $(\mathrm{m} / \mathrm{m}), q$ is the flow per unit of width $\left(\mathrm{m}^{2} / \mathrm{s}\right)$.

$54 \quad$ The maximum variation of depth due to

${ }^{55}$ wind effect can be calculated with equation 11 :

56

${ }_{57} \frac{d h}{h_{o}}=\frac{h_{w}-h_{o}}{h_{o}} \times 100$

58

59 in which $b_{0}$ is the depth of the permanent uniform

60 flow before wind action calculated with Manning

${ }^{61}$ Equation. $d h$ is the maximum depth variation due to

62 continuous wind action $(\mathrm{m})$ and $\frac{d h}{h_{o}}$ is the percentage

${ }^{63}$ variation of depth related to $h_{0}(\%)$.

64 It is important to highlight that the wind

${ }^{65}$ action is constant with no changes in velocity or

${ }^{66}$ direction and the flow is uniform with no changes in

${ }^{67}$ its characteristics. As the new depth value related to

68 the new steady state achieved after some time, it

${ }^{69}$ represents the maximum (minimum) depth that can

${ }^{70}$ be achieved due to wind acting against (along) the

71 flow direction.

72

${ }^{73}$ Abacus of maximum (minimum) depth due to ${ }^{74}$ wind acting against (along) the flow direction

76 The results of applying equations 10 and 11 are 77 displayed as two abacus for values of Manning coefficient ${ }^{78}$ of 0.03 (Figure 20) and 0.06 (Figure 21). The maximum

${ }^{79}$ percentage variation of water depth due to continuous wind

80 influence is plotted against wind speed (U) displaying several

${ }^{81}$ curves related to different flow per unit width (q). The

82 abacus contains 12 plots considering different bed slopes.

83 An additional figure showing maximum ${ }^{84}$ percentage variation of water depth plotted against bed 


\section{Preprint}

${ }^{1}$ slope is also presented to better understand the influence of $\quad{ }^{4}$

${ }^{2}$ bed slope on the disturbance caused by wind stress (Figure ${ }^{5}$

$\left.{ }^{3} 22\right)$.
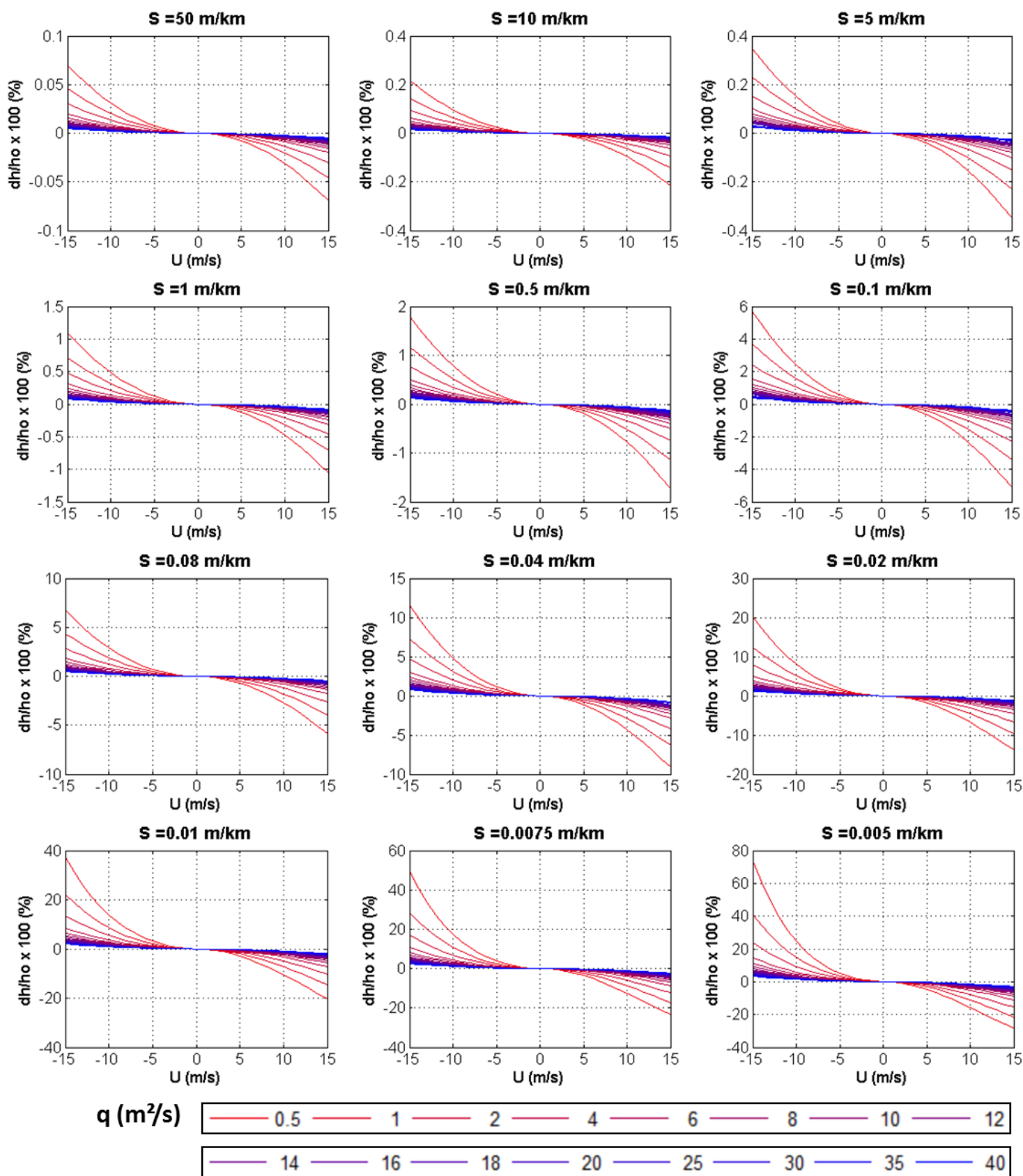

10 Figure 19 - Abacus that relates percentage depth variation with wind velocity (U) and flow by unit width (q) for different bed slope values (S) considering a Manning coefficient of 0.03 . 


\section{Preprint}
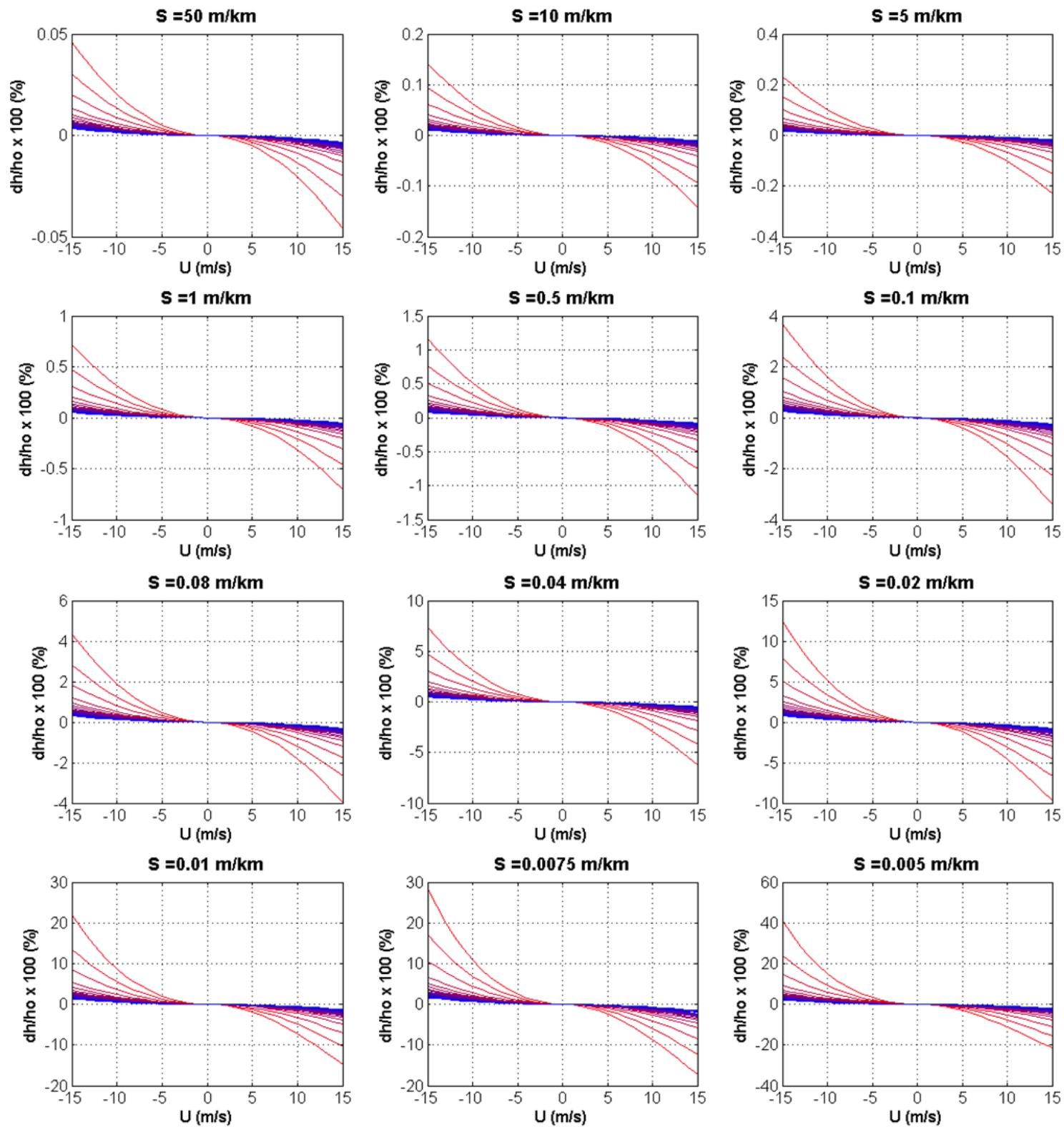

$$
\begin{aligned}
& \mathbf{q}\left(\mathrm{m}^{2} / \mathrm{s}\right) \quad 0.5-1-6-10-12 \\
& 14-16-18-20-30-35-40
\end{aligned}
$$

Figure 20 - Abacus that relates percentage depth variation with wind velocity (U) and flow by unit width (q) for different bed slope values (S) considering a Manning coefficient of 0.06 . 


\section{Preprint}
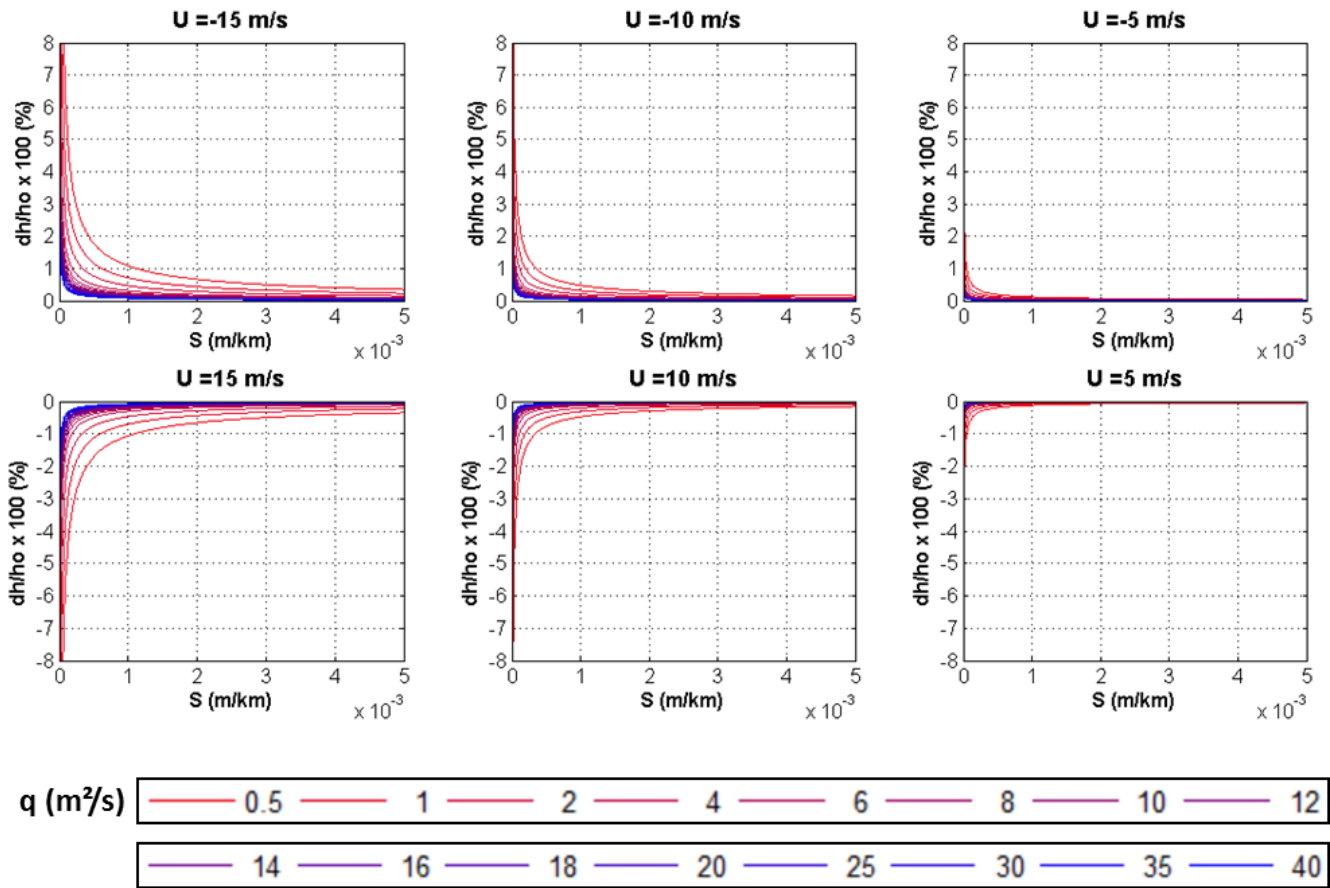

Figure 21 - Relationship between percentage depth variation and bed slope values (S), with curves representing different flow by unit width (q) values and plots for different wind velocities (U) considering a Manning coefficient of 0.03 .

The analysis of figures 20,21 and 22 provided ${ }^{7}$ some insights. The first one is that the greater is the value ${ }^{8}$ of flow per unit width, the lower is the maximum percentage ${ }^{9}$ variation of water depth associate with continuous wind ${ }^{10}$ stress. Hence, considering a river that presents similar values 11 of with under high and low flow conditions, this means that 12 percentage variations of depth due to wind action are greater 13 in low flow conditions.

14 As observed in the simulations, percentage ${ }^{15}$ variations of depth are greater when wind blows against the ${ }^{16}$ flow direction. This difference of percentage variations ${ }^{17}$ when comparing positive and negative wind velocities is ${ }^{18}$ more pronounced for higher disturbances in flow due to ${ }^{19}$ wind action.

As observed in the simulations, greater percentage ${ }^{21}$ depth variations are achieved with lower bed slopes. Figure 2222 aids the understanding of how this occurs. Considering ${ }^{23}$ slopes steeper than $1 \mathrm{~m} / \mathrm{km}$, alterations of water depth due ${ }^{24}$ to wind action are minimal and don't vary expressively with ${ }^{25}$ different values of slope (under this threshold). However,

${ }^{26}$ for mild slopes, variations of slope values cause expressive

27 differences of percentage variations of water depth; and

${ }^{28}$ when the bed slope tends to zero, the percentage depth

${ }^{29}$ variation due to wind action tend to infinite values.

30

\section{${ }^{31}$ CONCLUSIONS}

This study had the objective to evaluate the wind
${ }^{34}$ effect in $1 \mathrm{~d}$ hydrodynamic simulations, based in the local 35 inertial method.

36 At first glance, it was possible to include wind 37 influence in the algorithm of the inertial flow routing ${ }^{38}$ method and obtain a stable solution. The simulations ${ }^{39}$ provided results that aided the definition of an equation to ${ }^{40}$ predict maximum wind influence in river water depths ${ }^{41}$ depending on the river flow characteristics and wind 42 velocities.

43

From the results it was possible to conclude that:

44 - Continuous wind action causes an immediate 45 disturbance in $1 \mathrm{D}$ water flow which gradually returns to the ${ }^{46}$ previous flow value, achieving new permanent state of ${ }^{47}$ equilibrium with a different water depth. For negative ${ }^{48}$ (positive) wind velocities, which act against (along) the flow 49 direction, the disturbance in flow in negative (positive) ${ }^{50}$ causing an increase (decrease) in water depth.

51 - A pulse of wind action causes a peak in depth ${ }^{52}$ values if the wind velocity is negative and a minimum value ${ }^{53}$ in case the wind velocity is positive. Water flow presents ${ }^{54}$ both greater and lower values than the inflow. This happens ${ }^{55}$ because the system was subjected to a temporary forcing ${ }^{56}$ and must achieve a state of permanent equilibrium.

57 Greater values of Manning coefficient, flow per ${ }^{58}$ unit width, and bed slopes cause lower variations of water ${ }^{59}$ depth due to wind influence, as greater values of the wind

${ }^{60}$ friction coefficient cause the opposite result. 


\section{Preprint}

1 - Small oscillations in flow were perceived due to 2 the interaction with the boundary conditions. These ${ }^{3}$ oscillations are favored by the combination of the effects of ${ }^{4}$ greater flow celerity and greater magnitude of the ${ }^{5}$ disturbance caused by the wind stress. Considering ${ }^{6}$ conditions that decrease celerity and/or decrease the ${ }^{7}$ disturbance caused by wind action or using a longer river ${ }^{8}$ reach may dampen these oscillations.

$9 \quad-$ Values of the parameter $\alpha$ must be carefully ${ }^{10}$ chosen to prevent numerical instability, which can happen ${ }^{11}$ more easily under extreme wind velocity conditions.

12 - The greater the disturbance caused by the wind ${ }^{13}$ effect, the greater the time that the system takes to achieve 14 the new permanent flow condition under continuous wind ${ }^{15}$ action. Considering the pulse profile, greater disturbances ${ }^{16}$ take more time to be dissipated. The same behavior occurs ${ }^{17}$ for longer reaches, which shows the greater inertia of large ${ }^{18}$ hydrodynamic systems.

19 - The equation and the abacus proposed can be ${ }^{20}$ useful in engineering applications to estimate the maximum

${ }^{21}$ wind effect over water levels on a specific river. Therefore,

22 the abacus can aid to define if a river is likely to be

${ }^{23}$ influenced by the wind and if this factor should be

24 accounted for.

25 From these results, next steps of study will be the ${ }^{26}$ implementation and testing of the inertial solution

${ }^{27}$ considering the wind shear effects in a hydrologic-

${ }^{28}$ hydrodynamic model, for discharge simulation and flood

${ }^{29}$ forecasting considering this aspect.

\section{${ }^{31}$ REFERENCES}

${ }^{33}$ BACOPOULOS, P., HAGEN, S. C., COX, A. T.,

${ }^{34}$ DALLY, W. R., \& BRATOS, S. M. (2012).

35 Observation and simulation of winds and

36 hydrodynamics in St. Johns and Nassau Rivers.

${ }_{37}$ Journal of Hydrology, V. 420-421, p. 391-402.

${ }^{38}$ BATES, P. D., HORRIT'T, M. S., \& FEW'TRELL, T. J. (2010). A simple inertial formulation of the shallow water equations for efficient twodimensional flood inundation modelling. Journal of Hydrology, V. 387, p. 33-45.

${ }^{43}$ BLUMBERG, A. F., \& MELLOR, G. L. (1987). A

44 Description of a three-dimensional coastal ocean

45 circulation model. In: C.N.K. Mooers (Ed.),

46 Three-dimensional Coastal Ocean Models. Coastal

47 and Estuarine Sciences, V. 4, p. 1-16.
${ }^{48}$ BORCHE, A. (1996). IPH-A: Aplicativo para

49 modelação de estuários e lagoas - Manual de

50 Utilização do sistema. Publicação em Recursos

51 Hídricos $\mathrm{N}^{\circ}$ 33. IPH/UFRGS, $38 \mathrm{p}$.

${ }^{52}$ CHANSON, H. (2004). The Hydraulics of Open

53 Channel Flow: An Introduction. Oxford, UK:

${ }^{54}$ Butterworth-Heinemann, 2nd edition.

${ }^{55}$ CHOW, V. T., MAIDMENT, D. R., \& MAYS, L. W.

56 (1988). Applied Hydrology. McGraw Hill.

${ }^{57}$ COLLISCHONN, W., ALLASIA, D. G., SILVA, B.

$58 \quad$ C., \& TUCCI, C. E. (2007). The MGB-IPH model

59 for large-scale rainfall-runoff modelling.

60 Hydrological Sciences Journal, V. 52, p. 878-895.

${ }^{61}$ CUNGE, J. A. (1969). On the Subject of a Flood

62 Propagation Computation Method (Munkingum

63 Method). Journal of Hydraulic Research, V. 7, p.

$64 \quad 205-230$

${ }^{65}$ CUNGE, J. A., HOLLY, F. M., \& VERWEY, A.

${ }_{66}$ (1980). Practical Aspects Computational River

67 Hydraulics. London: Pitman Publishing.

${ }_{68}^{68}$ 'AQUINO, C. A., FRANKLIN DA SILVA, L., 69 COUCEIRO, M. A., \& PEREIRA, M. D. (2011).

70 Transporte de Sal e Hidrodinâmica do Estuário

71 do Rio Tubarão - SC, Brasil. RBRH - Revista

72 Brasileira de Recursos Hídricos, V. 16, n.3, p. 113-

$73 \quad 125$.

${ }^{74}$ DECHARME, B., DOUVILLE, H., PRIGENT, C.,

75 PAPA, F., \& AIRES, F. (2008). A new river

76 flooding scheme for global climate applications:

77 off-line evaluation over South America. J.

78 Geophys. Res., V. 113.

${ }^{79}$ DELTARES. (2014). Delft3D-FLOW - Simulation of

80 multi-dimensional hydrodynamic flows and

81 transport phenomena, including sediments- User

82 Manual. Version: 3.15.34158. Delft, The

83 Netherlands.

${ }^{84}$ DHI. (2011). MIKE 21 \& MIKE 3 Flow Models -

${ }_{85}$ hydrodynamic and Transport Module: Scientific

${ }_{86}$ Documentation. http://www.mikebydhi.com.

${ }^{87}$ ESCOBAR, G., VARGAS, W., \& BISCHOFF, S.

${ }_{88}$ (2004). Wind tides in the Rio de la Plata estuary: 
1 meteorological conditions. Int. J. Climatol., V. 24, 2 p. 1159-1169.

${ }^{3}$ FAN, F. M., PONTES, P. R., PAIVA, R. C., \& 4 COLLISCHONN, W. (2014). Avaliação de um 5 método de propagação de cheias em rios com 6 aproximação inercial das equações de Saint7 Venant. RBRH - Revista Brasileira de Recursos $8 \quad$ Hídricos. Volume 19, n. 4, 137-147.

${ }^{9}$ FRAGOSO JR., C. R., NES, E. V., JENSE, J. H., \& 10 MARQUES, D. M. (2009). IPH-TRIM3D-

11 PCLake: A three-dimensional complex dynamic

12 model. Environmental Modelling \& Software, V.

$13 \quad$ 24(11), p. 1347-1348.

${ }^{14}$ GONG, W., SHEN, J., \& HONG, B. (2009). The 15 influence of wind on the water age in the tidal 16 Rappahannock River. Marine Environmental 17 Research, V. 68, p. 203-216.

${ }^{18}$ HATTERMANN, F. F., WATTENBACH, M., 19 KRYSANOVA, V., \& WECHSUNG, F. (2005).

20 Runoff simulations on the macroscale with the

21 ecohydrological model SWIM in the Elbe

22 catchmentevalidation and uncertainty analysis.

23 Hydrol. Process. , V. 19 (3), p. 693-714.

${ }^{24}$ HODGES, B. R. (2013). Challenges in Continental

25 River Dynamics. Environmental Modelling \&

26 Software, V. 50, p. 16-20.

${ }^{27}$ JI, Z. G. (2008). Hydrodynamics and Water Quality:

28 Modeling Rivers, Lakes and Estuaries. Hoboken,

29 New Jersey: John Wiley \& Sons, Inc.

${ }^{30}$ LOPES, V. A. (2015). Modelagem hidrológica

${ }_{31}$ integrada da bacia hidrográfica da Laguna dos

32 Patos e seus complexos lagunares usando o

33 modelo MGB-IPH com propagação inercial de

$34 \quad$ vazões. Porto Alegre: Monografia. Universidade

35 Federal do Rio Grande do Sul (UFRGS).

36 Departamento de Engenharia.

${ }^{37}$ LOPES, V. A. (2017). Modelagem hidrológica e

38 hidrodinâmica integrada de bacias e sistemas

39 lagunares com influência do vento. 2017.

40 Dissertação (Mestrado em Recursos Hídricos e

41 Saneamento Ambiental) - Universidade Federal do

42 Rio Grande do Sul, Conselho Nacional de

43
${ }^{44}$ MASHRIQUI, H. S., S, H. J., \& M, R. (2014). A 1D

$45 \quad$ River Hydraulic Model for Operational Flood

46 Forecasting in the Tidal 3 Potomac: Evaluation

47 for Freshwater, Tidal, and Wind Driven Events.

48 Journal of Hydraulic Engineering Vol. 140 No4.

${ }^{49}$ MCCARTHY, G. T. (1938). The unit hydrograph and

50 flood routing. Conference of North Atlantic

51 Division, US Army Corpsof Engineers. New

52 London: CT. US Engineering.

${ }^{53}$ MONTERO, R. A., SCHWANENBERG, D.,

${ }^{54}$ HATZ, M., \& BRINKMANN, M. (2013).

55 Simplified hydraulic modelling in model predictive

56 control of flood mitigation measures along rivers.

57 Journal of Applied Water Engineering and

58 Research, V. 1, p. 17-27.

${ }^{59}$ NEITSCH, S. L., ARNOLD, J. G., KINIRY, J. R., 60 WILLIAMS, J. R., \& KING, K. W. (2002). Soil 61 and water assessment tool - theorical

62 documentation, version 2000. Temple, Grassland,

63 Soil and Eater Research Laboratory - Agricultural

${ }_{64}$ Research Service (p. 212 p.). Blackland Research

65 Center - Texas Agricultural Experiment Station.

${ }^{66}$ NGO-DUC, T., LAVAL, K., RAMILLIEN, G., \&

67 POLCHER, J. (2007). Validation of the land

68 water storage simulated by ORCHIDEE with

69 GRACE data: role of the routing scheme. Water

70 Resources Research, 43(4):W04427,

71 doi:10.1029/2006WR004941.

${ }^{72}$ PAZ, A. R., REIS, L. G., \& LIMA, H. V. (2005). Uso

73 de modelagem hidrodinâmica visando a

74 segmentação de corpos d'água rasos para

75 enquadramento: o caso do Lago Guaíba (RS). In:

76 XVI Anais do Simpósio Brasileiro de Recursos

77 Hídricos. João Pessoa, 20 a 24 de novembro de

782005

${ }^{79}$ PONTES, P. R., COLLISCHONN, W., FAN, F. M., PAIVA, R. C., \& BUARQUE, D. C. (2015).

81 Modelagem Hidrológica e Hidráulica de Grande

82 Escala com Propagação Inercial de Vazões.

83 RBRH - Revista Brasileira de Recursos Hídricos.

${ }^{84}$ PONTES, P. R., FAN, F. M., FLEISCHMANN, A.

85 S., PAIVA, R. C., BUARQUE, D. C.,

86 SIQUEIRA, V. A., et al. (2017). MGB-IPH model

87 for hydrological and hydraulic simulation of large 


\section{Preprint}

floodplain river systems coupled with open source GIS. Environmental Modelling \& Software, V. 94, p. 1-20.

${ }^{4}$ RAMÓN, C. L., PRATS, J., \& RUEDA, F. J. (2016).

5 The influence of flow inertia, buoyancy, wind, and

6 flow unsteadiness on mixing at the asymmetrical

7 confluence of two large rivers. Journal of

8 Hydrology, V. 539, p. 11-26.

${ }^{9}$ USACE. (2010). HEC-RAS River Analysis System:

10 Hydraulic Reference Manual Ver. 4.1. 609 Second

11 Street, Davis, CA 95616: U.S. Army Corps of

12 Engineers, Hydrologic Engineering Center.
${ }^{13}$ WU, J. (1982). Wind-stress coefficients over sea 14 surface from breeze to hurricane. J. Geophys. $15 \quad$ Res., V. 87, C12, p. 9704-9706.

${ }^{16}$ YAMAZAKI, D., DE ALMEIDA, G. A., \& BATES, P. D. (2013). Improving computational efficiency

18 in global river models by implementing the local

19 inertial flow equation and a vector-based river

20 network map. Water Resources Research, V.

$21 \quad 49(11)$, p. 7221-7235. 